\title{
Preparation and characterization of self-assembled nanoparticles based on low-molecular-weight heparin and stearylamine conjugates for controlled delivery of docetaxel
}

\author{
This article was published in the following Dove Press journal: \\ International Journal of Nanomedicine \\ 8 December 2014 \\ Number of times this article has been viewed
}

\author{
Dong-Hwan Kim' \\ Ubonvan Termsarasab' \\ Hyun-Jong Cho ${ }^{2}$ \\ In-Soo Yoon ${ }^{3}$ \\ Jae-Young Lee' \\ Hyun Tae Moon' \\ Dae-Duk Kim' \\ 'College of Pharmacy and Research \\ Institute of Pharmaceutical Sciences, \\ Seoul National University, Seoul, \\ Republic of Korea; ${ }^{2}$ College of \\ Pharmacy, Kangwon National \\ University, Chuncheon, Republic \\ of Korea; ${ }^{3}$ College of Pharmacy \\ and Natural Medicine Research \\ Institute, Mokpo National University, \\ Jeonnam, Republic of Korea
}

\begin{abstract}
Low-molecular-weight heparin (LMWH)-stearylamine (SA) conjugates (LHSA)-based self-assembled nanoparticles were prepared for intravenous delivery of docetaxel (DCT). 1-Ethyl-3-(3-dimethylaminopropyl) carbodiimide and $N$-hydroxysuccinimide were used as coupling agents for synthesis of LHSA conjugates. The physicochemical properties, in vitro antitumor efficacy, in vitro cellular uptake efficiency, in vivo antitumor efficacy, and in vivo pharmacokinetics of LHSA nanoparticles were investigated. The LHSA nanoparticles exhibited a spherical shape with a mean diameter of 140-180 nm and a negative surface charge. According to in vitro release and in vivo pharmacokinetic test results, the docetaxel-loaded LHSA5 (LMWH:SA =1:5) nanoparticles exhibited sustained drug release profiles. The blank LHSA nanoparticles demonstrated only an insignificant cytotoxicity in MCF-7 and MDAMB 231 human breast cancer cells; additionally, higher cellular uptake of coumarin 6 (C6) in MCF-7 and MDAMB 231 cells was observed in the LHSA5 nanoparticles group than that in the C6 solution group. The in vivo tumor growth inhibition efficacy of docetaxel-loaded LHSA5 nanoparticles was also significantly higher than the Taxotere ${ }^{\circledR}$-treated group in the MDAMB 231 tumor-xenografted mouse model. These results indicated that the LHSA5-based nanoparticles could be a promising anticancer drug delivery system.
\end{abstract}

Keywords: amphiphilic polymer, docetaxel, drug delivery, low-molecular-weight heparin, self-assembled nanoparticle

\section{Introduction}

Over the past decade, nanoparticulate drug delivery systems containing anticancer agents have been investigated extensively due to their specific accumulation behavior at the tumor site. ${ }^{1,2}$ Nanoparticulate drugs can be distributed to tumor vasculatures by the enhanced permeability and retention (EPR) effect, taking advantage of the leaky vascular nature of tumor tissues that provides for passive tumor targeting. ${ }^{3,4}$ Additionally, these nanoparticulate drugs offer the advantages of prolonged systemic circulation by avoiding phagocytosis, improved efficacy, and reduced toxicity. Numerous biocompatible and biodegradable materials, such as poly(lactic acid), ${ }^{5,6}$ poly(glycolic acid),${ }^{7}$ polycaprolactone,${ }^{8,9}$ polysaccharides,,${ }^{10}$ proteins, ${ }^{11}$ and polypeptides, ${ }^{12}$ have been used for the preparation of polymeric nanoparticles. Among them, polysaccharides have been used extensively to prepare nanoparticles for drug delivery. ${ }^{2}$ Polysaccharides are natural biomaterials; thus, they are generally safe, nontoxic, biocompatible, and biodegradable. They have various derivable groups that can be modified with other
Correspondence: Dae-Duk Kim College of Pharmacy and Research Institute of Pharmaceutical Sciences, Seoul National University, Seoul I5I-742, Republic of Korea

Tel +82 28807870

Fax +8228739177

Email ddkim@snu.ac.kr 
chemicals. Among the drug delivery systems, self-assembled nanoparticles have been studied for the encapsulation and sustained release of poorly soluble drugs. ${ }^{13-15}$ Amphiphilic polymers can be used to form nanoparticles with a hydrophobic core and a hydrophilic shell. This structure enables the encapsulation and delivery of poorly soluble drugs, extending the circulation time of nanoparticles in the bloodstream.

Docetaxel (DCT), an antimitotic chemotherapy medication and a semisynthetic analog of paclitaxel, is a particularly important anticancer agent that has been used for the treatment of many cancers, exhibiting cytotoxic activity in breast, ovarian, prostate, and non-small-cell lung cancer cells. ${ }^{16-18}$ As with all chemotherapies, however, adverse effects are common; side effects such as neutropenia, peripheral neuropathy, musculoskeletal toxicity, and hypersensitivity reactions have been verified. In its commercial formulation (Taxotere $^{\circledR}$, Sanofi-Aventix, Bridgewater, NJ, USA), nonionic surfactant Tween 80 (polysorbate 80 ) and 13\% ethanol in saline have been used to dissolve DCT, due to its poor solubility in water, ${ }^{19}$ however, this formulation is associated with unpredictable hypersensitivity reactions and other side effects. $^{20}$ Thus, many new systems - including micelles, emulsions, and conjugates with other polymers - have been developed to deliver DCT to tumor sites with minimal adverse reactions..$^{21-23}$

Heparin is a biocompatible, biodegradable, water-soluble natural polysaccharide coupled with various biological activities, including anticoagulation, anti-inflammatory, and antiangiogenesis effects. ${ }^{24,25}$ In addition to its well-known anticoagulant activity, the anticancer activity of heparin has been evaluated. ${ }^{26,27}$ Low-molecular-weight heparin (LMWH) exerts its anticancer activity by affecting the proliferation, adhesion, angiogenesis, migration, and invasion of cancer cells. Although the exact mechanism of LMWH interference with cancer biology still remains unclear, it may involve the inhibition of both coagulation and noncoagulation-dependent pathways of tumor progression. ${ }^{28}$ Furthermore, in a study of venous thromboembolism therapy, a significant reduction in the mortality rate was noted in the LMWH treatment group among cancer patients. ${ }^{26}$ Thus, these idiosyncratic properties facilitate the development of heparin-based delivery systems. ${ }^{29,30}$ However, unfractionated heparin (UFH) causes adverse effects, such as bleeding, which have limited its application. LMWH has a reduced anticoagulant activity and, thus far, appears to have a greater anticancer effect than UFH; ${ }^{31}$ thus, LMWH is preferable to UFH for the initial treatment of venous thromboembolism prevalent in cancer patients. $^{32}$
In this study, we synthesized an amphiphilic polymer composed of LMWH and stearylamine (octadecylamine, SA) for the preparation of self-assembled nanoparticles for anticancer drug delivery. This negatively charged nanoparticle was prepared using LMWH-SA (LHSA) conjugates, with LMWH as the hydrophilic segment and SA as its hydrophobic counterpart. SA (18-carbon saturated fatty amine) is used for the synthesis of uniform nanoparticles. ${ }^{33}$ The physicochemical properties of LHSA-based nanoparticles containing DCT were characterized by determining size, zeta potential, and DCT-loading efficacy. DCT release from nanoparticles and the cytotoxicity of blank nanoparticles were also investigated. Moreover, the optimized formulation was evaluated via in vitro cellular uptake study using confocal laser scanning microscopy (CLSM) and fluorescence-activated cell sorter (FACS) measurements, and in vivo antitumor efficacy and pharmacokinetic studies.

\section{Materials and methods Materials}

LMWH (101 IU mg-1), with an average molecular weight of 4,500 Da, was purchased from Nanjing King-Friend Biochemical Pharmaceutical Co. Ltd (Nanjing, People's Republic of China). 1-Ethyl-3-(3-dimethylaminopropyl) carbodiimide (EDC), $N$-hydroxysuccinimide (NHS), SA, coumarin 6 (C6), and pyrene were obtained from SigmaAldrich Co. (St Louis, MO, USA). DCT was purchased from Taihua Co. (Xi'an, People's Republic of China). Formamide (FA), tetrahydrofuran (THF), and acetonitrile (HPLC [highperformance liquid chromatography] grade) were supplied by Fisher Scientific Korea Ltd. (Seoul, Republic of Korea). Dulbecco's Modified Eagle's Medium (DMEM), RPMI 1640 (developed by Roswell Park Memorial Institute), heatinactivated fetal bovine serum, streptomycin, and penicillin were obtained from Gibco Life Technologies (Karlsruhe, Germany). Water was purified by distillation, deionization, and reverse osmosis (Milli-Q Plus). All other chemicals were of analytical grade, which were purchased from commercial sources.

\section{Synthesis and characterization of LHSA conjugates}

Amphiphilic LHSA conjugates were synthesized from LMWH and SA. LMWH (1 g) was dissolved in FA $(200 \mathrm{~mL})$ by gentle heating. To synthesize the LHSA conjugates, LMWH solutions were mixed with different amounts of EDC and NHS ( $3 \mathrm{~mol} / \mathrm{mol}$ of SA, each) at room temperature. The solutions were then added with different amounts of SA 
$(1,3$, and $5 \mathrm{~mol} / \mathrm{mol}$ of LMWH) dissolved in THF (132 mL), followed by stirring at room temperature for 24 hours. The mixtures were then precipitated in excess cold acetone (at $5 \times$ the mixture volume) under vigorous agitation, filtered by a glass filter (G4), and stirred for 30 minutes. To remove excess EDC, NHS, and SA, the residues on the glass filter were carefully washed three times with cold acetone, followed by filtering with $50 \mathrm{~mL}$ of distilled deionized water (DDW). The filtrate was dialyzed against DDW for 48 hours using a dialysis membrane with molecular weight cutoff of $1 \mathrm{kDa}$ (Spectrum Laboratories, Laguna Hills, CA, USA) and lyophilized. The LHSA conjugate was dissolved in $\mathrm{D}_{2} \mathrm{O}$ and analyzed by proton nuclear magnetic resonance ( $\left.{ }^{1} \mathrm{H}-\mathrm{NMR}\right)$ spectroscopy (500 MHz).

Aliquots of conjugates were dissolved in $\mathrm{D}_{2} \mathrm{O}\left(10 \mathrm{mg} \mathrm{mL}^{-1}\right)$, and ${ }^{1} \mathrm{H}-\mathrm{NMR}$ spectra were obtained by using a Varian FT 500-MHz NMR spectrometer (Varian Inc., Palo Alto, CA, USA). The values of the proton peaks from the ${ }^{1} \mathrm{H}-\mathrm{NMR}$ spectra were integrated to determine the molar substitution of LHSA. Linear regression was prepared from the physical mixture of LMWH and SA at various molar ratios (LMWH:SA $=0.5: 1,1: 1,1: 2$, and 1:4) dissolved in the mixture of $\mathrm{D}_{2} \mathrm{O} / \mathrm{THF}-\mathrm{d} 8(1: 1)$. The ratio of the integration area $(2.80 / 1.95 \mathrm{ppm})$ of each physical mixture was calculated.

The anticoagulant activity of LMWH and the LHSA conjugates was determined using the Coatest anti-FXa chromogenic assay (Chromogenix, Milan, Italy). The critical micellar concentration (CMC) of LHSA was investigated using pyrene as a fluorescence probe, as described previously. ${ }^{34}$ A pyrene solution in THF $\left(2 \times 10^{-6} \mathrm{M}\right)$ was prepared, and the THF was evaporated under gentle nitrogen gas $\left(\mathrm{N}_{2}\right)$ flow for 1 hour at $60^{\circ} \mathrm{C}$. An LHSA solution in DDW $(1 \mathrm{~mL})$, in the concentration range of $10^{-5}$ to $1 \mathrm{mg} \mathrm{mL}^{-1}$, was added to each tube to achieve a final pyrene concentration of $6 \times 10^{-7} \mathrm{M}$. The intensity ratio $\left(\mathrm{I}_{1} / \mathrm{I}_{3}\right)$ in the excitation spectra was calculated and plotted. The excitation wavelength was fixed at $334 \mathrm{~nm}$ after scanning from 350 to $550 \mathrm{~nm}$, and the slit openings for excitation and emission were set at 10 and $3 \mathrm{~nm}$, respectively. Fluorescence measurements were performed using a fluorescent spectrometer FP-6500 (JASCO Co., Tokyo, Japan).

\section{Preparation and characterization of LHSA-based nanoparticles}

A simple modification of our previous methods was used for the self-assembly of LHSA and drug encapsulation. ${ }^{34}$ LHSA ( $5 \mathrm{mg}$ ) and $1 \mathrm{mg}$ of DCT were completely solubilized in $1 \mathrm{~mL}$ of $\mathrm{FA}$; the solvent was evaporated under gentle $\mathrm{N}_{2}$ flow for 5 hours at $80^{\circ} \mathrm{C}$. LHSA and DCT-coated tubes were resuspended with $1 \mathrm{~mL}$ of DDW by vortexing for 3 minutes, followed by filtering through a $0.22 \mu \mathrm{m}$ pore-size syringe filter (Minisart RC 15, Sartorius Stedium Biotech GmbH, Goettingen, Germany).

The mean diameter, polydispersity, and zeta potential of the nanoparticles were determined using a light scattering spectrophotometer (ELS-Z, Otsuka Electronics, Osaka, Japan) at a polymer concentration of $5 \mathrm{mg} \mathrm{mL}^{-1}$. The morphology of the LHSA nanoparticles was assessed by transmission electron microscopy (TEM) (JEM 1010, JEOL, Tokyo, Japan). The nanoparticle suspensions were stained with $2 \%(\mathrm{w} / \mathrm{v})$ phosphotungstic acid, placed on a copper grid coated with carbon film, air-dried for 10 minutes, and photographed.

The nanoparticle suspensions were distilled with FA to disrupt the self-assembled structure. The drug encapsulation efficiency of drug-loaded nanoparticles was measured using HPLC. ${ }^{34}$ The HPLC instrument consisted of a dual pump (Waters 515, Waters Corporation, Milford, MA, USA), an autosampler (Waters 717 plus, Waters Corporation), an ultraviolet detector (Waters 2487, Waters Corporation), and a reverse-phase C- 18 column $\left(250 \times 4.4 \mathrm{~mm}^{2}, 5 \mu \mathrm{m}\right.$, Shiseido, Japan). The mobile phase was a mixture of acetonitrile and $\operatorname{DDW}(55: 45, \mathrm{v} / \mathrm{v})$. The eluent was monitored at $230 \mathrm{~nm}$ and

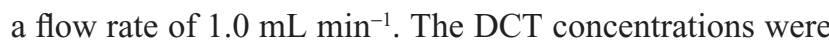
determined using $20 \mu \mathrm{L}$ of injection volume at room temperature. The lower limit of quantitation was $500 \mathrm{ng} \mathrm{mL}^{-1}$.

\section{In vitro DCT release studies}

The LHSA5 nanoparticles (the volume equivalent of $100 \mu \mathrm{g}$ of DCT) were loaded in semipermeable Mini-Gebaflex-tubes with a molecular weight cutoff of 6-7 kDa (Gene Bio-Application Ltd., Kfar Hanagid, Israel) and were immersed in the medium $(10 \mathrm{~mL})$. The dissolution medium was phosphatebuffered saline (PBS, pH: 7.4) containing 0.5\% (w/v) Tween 80 at $37^{\circ} \mathrm{C}$, and was rotated at $50 \mathrm{rpm}$. Aliquots $(0.2 \mathrm{~mL})$ of medium were collected at predetermined times $(1,2,3$, $4,6,9,12,24,48,72,96$, and 144 hours), and fresh media $\left(37^{\circ} \mathrm{C}\right)$ of equal volume was added to maintain sink condition. The amounts of DCT released into the medium were analyzed by HPLC.

\section{In vitro cytotoxicity of conjugate}

MCF-7 and MDAMB 231 cells were purchased from the Korean cell line bank (Seoul, Republic of Korea) and were cultured in RPMI-1640 medium with $1 \%(\mathrm{v} / \mathrm{v})$ penicillin (100 $\left.\mathrm{U} \mathrm{mL}^{-1}\right)$, streptomycin $\left(0.1 \mathrm{mg} \mathrm{mL}^{-1}\right)$, and $10 \%(\mathrm{v} / \mathrm{v})$ 
fetal bovine serum. They were incubated in a humidified 5\% $\mathrm{CO}_{2}$ atmosphere at $37^{\circ} \mathrm{C}$.

The cytotoxicity of LHSA5 conjugate polymer was evaluated in MCF-7 and MDAMB 231 cells by using MTS-based assays. MCF-7 and MDAMB 231 cells $\left(1 \times 10^{4}\right.$ cells $)$ were seeded in 96-well plates. Various concentrations of LHSA5 polymer in the culture medium were incubated for 24 hours at $37^{\circ} \mathrm{C}$, after which the cells were treated with an MTS-based CellTiter $96 \mathrm{AQ}_{\text {ueous }}$ One Solution Cell Proliferation Assay reagent (Promega Corp., Fitchburg, WI, USA) for 4 hours at $37^{\circ} \mathrm{C}$ following the manufacturer's protocol. The absorbance of the medium was read at $490 \mathrm{~nm}$ using the Emax Precision Microplate Reader (Molecular Devices LLC, Sunnyvale, CA, USA).

\section{In vitro antitumor efficacy studies}

In vitro antitumor efficacy was evaluated using MTS-based assays. MCF-7 and MDAMB 231 cells $\left(1 \times 10^{4}\right.$ cells $)$ were seeded in 96-well plates for 24 hours. After washing the cells twice with PBS, they were incubated with various concentrations $(0.1,1.0$, and $5.0 \mu \mathrm{M})$ of DCT solution (Taxotere, Sanofi-Aventis) or DCT-loaded LHSA5 nanoparticles for 24 hours at $37^{\circ} \mathrm{C}$. Then, the cells were treated with an MTS-based CellTiter $96 \mathrm{AQ}_{\text {ueous }}$ One Solution Cell Proliferation Assay reagent (Promega) for 4 hours at $37^{\circ} \mathrm{C}$ following the manufacturer's instructions. The absorbance at $490 \mathrm{~nm}$ was read using an Emax Precision Microplate Reader (Molecular Devices LLC), and is expressed as percentage of viable cells compared with the control group (ie, without DCT).

\section{Cellular uptake studies}

The cellular uptake efficiency of the LHSA5 nanoparticles was investigated by CLSM with C6-loaded nanoparticles. ${ }^{34}$ C6 was also loaded in nanoparticles using a similar DCT loading method. Either MCF-7 or MDAMB 231 cells were seeded on culture plates (BD Falcon, Bedford, MA, USA) at a density of $1 \times 10^{5}$ per well $\left(1.7 \mathrm{~cm}^{2}\right.$ surface area) and incubated for 24 hours at $37^{\circ} \mathrm{C}$. C6 $(2 \mu \mathrm{g})$ was added alone or entrapped in the LHSA5 nanoparticles and incubated for 2 hours at $37^{\circ} \mathrm{C}$. Then, the cells were washed with PBS ( $\mathrm{pH}:$ 7.4) and were fixed with formaldehyde solution $(4 \%, v / v)$ for 10 minutes. After completely drying the liquid content, a VECTASHIELD mounting medium with 4',6diamidino-2-phenylindole (H-1200 Vector Laboratories, Inc., Burlingame, CA, USA) was added to prevent fading. Finally, the cells on the slides were observed using CLSM (LSM 510, Carl-Zeiss, Thornwood, NY, USA).
The cellular uptake efficiency of the LHSA5 nanoparticles was also determined by flow cytometry. MCF-7 and MDAMB 231 cells were seeded on 24-well plates at a density of $5 \times 10^{5}$ per well and incubated overnight at $37^{\circ} \mathrm{C}$. After removing the culture medium, the cells were incubated with free C6 or C6-loaded LHSA5 nanoparticles for 2 hours. The cells were then completely washed with PBS (pH: 7.4). After they were detached and centrifuged, the supernatant was removed. The cell pellets were suspended again with PBS containing $2 \%(\mathrm{v} / \mathrm{v})$ fetal bovine serum. The uptake efficiency was analyzed by a BD FACSCalibur flow cytometry system equipped with the Cell Quest Pro software (Becton Dickinson Bioscience, San Jose, CA, USA).

\section{In vivo antitumor efficacy}

Tumor-xenografted mouse model was prepared using female BALB/c nude mice (5 weeks old; Charles River, Washington, MA) for in vivo anticancer efficacy evaluation. The mice were kept in a light-controlled room at $22^{\circ} \mathrm{C} \pm 2{ }^{\circ} \mathrm{C}$ temperature and $55 \% \pm 5 \%$ relative humidity (Animal Center for Pharmaceutical Research, College of Pharmacy, Seoul National University, Seoul, Republic of Korea). The experimental protocols were approved by the Animal Care and Use Committee of the College of Pharmacy, Seoul National University. Tumor-xenografted mice were prepared by subcutaneous injection of MDAMD 231 cells $\left(3 \times 10^{6}\right.$ cells per mouse) in the right lateral flank. After measuring the tumor size with Vernier calipers, the tumor volume $\left(\mathrm{mm}^{3}\right)$ was calculated by the following formula: volume $=0.5 \times$ longest diameter $\times$ shortest diameter ${ }^{2}$. After 14 days, when the MDAMB 231 tumor became palpable, tumor volume and body weight measurements were commenced. The mice were randomly divided into four groups: the control (no treatment), blank LHSA5 nanoparticles, DCT solution (Taxotere), and DCT-loaded LHSA5 nanoparticles groups. DCT solution or DCT-loaded LHSA5 nanoparticles were intravenously injected at a dose of $30 \mathrm{mg} \mathrm{kg}^{-1}$ as DOC on days 0,7 , and 14 . Tumor volume and body weight were measured for 18 days.

\section{In vivo pharmacokinetic study in rats}

Male Sprague Dawley rats (280-300 g body weight) were used for pharmacokinetic studies. Under light anesthesia (30 mg kg-1 Zoletil ${ }^{\circledR}$, intramuscular injection, Virbac Korea Co. Ltd, Seoul, Republic of Korea), the femoral artery and vein of each rat were cannulated with a polyethylene tube (PE-50; Clay Adams, Parsippany, NJ, USA). DCT solution (Taxotere) or DCT-loaded LHSA5 nanoparticles $\left(8 \mathrm{mg} \mathrm{kg}^{-1}\right.$ 
as DCT) were administered to rats via the femoral vein within 1 minute. Blood samples $(-300 \mu \mathrm{L})$ were collected via the femoral artery at 0 (control), 1, 5, 15, 30, 60, 120, 180, 240, 360 , and 720 minutes after intravenous administration of Taxotere and DCT-loaded LHSA5 nanoparticles. After centrifugation of the blood samples, aliquots of plasma $(100 \mu \mathrm{L})$ were stored at $-70^{\circ} \mathrm{C}$ (Model DF8517; Ilshin Laboratory Co., Seoul, Republic of Korea) until liquid chromatography-mass spectrometry/mass spectrometry (LC-MS/MS) analysis of DCT. Immediately after each blood sampling, equal volume of $0.9 \%$ sodium chloride injectable solution containing $20 \mathrm{U} \mathrm{mL}^{-1}$ of heparin was injected.

The concentration of DCT in the plasma samples was determined by LC-MS/MS. The LC-MS/MS system consisted of an Agilent 1260 series HPLC system (equipped with a G1312B binary pump, a G1367E high-performance autosampler, a G1322A vacuum degasser, a G1330B FC/ALS thermostat, and a G1316C TCC, Agilent Technologies, Santa Clara, CA, USA), an Agilent 6430 triple quadrupole mass spectrometer (Agilent Technologies), and the MassHunter Workstation software (version B.03.01, Agilent Technologies).

Plasma samples $(100 \mu \mathrm{L})$ were deproteinized with acetonitrile $(300 \mu \mathrm{L})$ and methanol $(100 \mu \mathrm{L})$ containing $1 \mu \mathrm{L} \mathrm{mL} \mathrm{m}^{-1}$ paclitaxel (as an internal standard). They were vortexed and centrifuged at $16,000 \times g$ for 10 minutes. The supernatant $(400 \mu \mathrm{L})$ was transferred to a clean tube and completely evaporated under a gentle stream of $\mathrm{N}_{2}$ gas at room temperature. Then, the residue was reconstituted with $60 \mu \mathrm{L}$ of the mobile phase. After vortexing and centrifugation again, a $10 \mu \mathrm{L}$ aliquot of supernatant was injected into a poroshell $120 \mathrm{EC}-\mathrm{C} 16$ column $(2.7 \mu \mathrm{m}, 4.6 \times 50 \mathrm{~mm}$, Agilent Technologies) under isocratic elution of the mobile phase consisting of ammonium formate and acetonitrile $(30: 70, \mathrm{v} / \mathrm{v})$ at a flow rate of $0.2 \mathrm{~mL} \mathrm{~min}{ }^{-1}$. The column temperature was maintained at $30^{\circ} \mathrm{C}$. Data were acquired with electrospray ionization in the positive mode. Reaction monitoring was used to monitor the transitions from molecular ion to dominant product ion at charge-to-mass ratio of $(\mathrm{m} / \mathrm{z}) 808$ to 527 for DCT and $m / z 876$ to 591 for paclitaxel, respectively. The lower limit of quantitation value of DCT in rat plasma

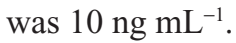

The following pharmacokinetic parameters were calculated using WinNonlin ${ }^{\circledR}$ (Pharsight, Mountain View, CA, USA): total area under the plasma concentration-time curve from time zero to the end time point (AUC), terminal half-life $\left(t_{1 / 2}\right)$, time-averaged total body clearance (CL), the apparent volume of the distribution under steady-state conditions $\left(V_{\mathrm{ss}}\right)$, and the mean residence time.

\section{Statistical analysis}

Statistical analyses were performed using analysis of variance. $P$-values $<0.05$ indicated statistical significance. All experiments were performed at least three times, and the data were presented as the mean \pm standard deviation.

\section{Results}

\section{Synthesis and characterization of LHSA conjugates}

Heparin and its derivatives have been widely used as drug delivery systems. ${ }^{35-37}$ In this study, SA (an aminated fatty acid) was conjugated to LMWH to produce an amphiphilic polymer, which is to form the self-assembled nanoparticles in aqueous environment (Figure 1A). As shown in Figure 1B, the amine group of SA was covalently coupled to the carboxylic group of LMWH in the presence of EDC and NHS, thus producing amphiphilic LHSA conjugates. In this coupling reaction, several LHSA conjugates were synthesized by adjusting the feed ratio of SA (mol) to LMWH (g) (LHSA1-LMWH:SA =1:1, LHSA3-LMWH:SA =1:3, and LHSA5-LMWH:SA =1:5). The synthesized LHSA conjugates were confirmed by ${ }^{1} \mathrm{H}-\mathrm{NMR}$ analysis, as shown in Figure 2 (Figure 2A, LMWH; Figure 2B, LHSA1; Figure 2C, LHSA3; Figure 2D, LHSA5; Figure 2E, SA). The ${ }^{1} \mathrm{H}-\mathrm{NMR}$ spectra of the LHSA conjugate exhibited proton signals for both LMWH and SA; a broad proton peak was observed for LMWH, and the presence of SA in the LHSA conjugate was confirmed by its chemical shift at $0.8-1.2 \mathrm{ppm}$. An alkyl chain $\left(-\mathrm{CH}_{2}-\right)$ and a terminal methyl group $\left(-\mathrm{CH}_{3}\right)$ of $\mathrm{SA}$ corresponded to the proton peaks at 1.10 and $0.90 \mathrm{ppm}$, respectively. These results indicated that the degree of substitution of LHSA increased with an increase in the feed ratio of SA. The physical mixtures of LMWH and SA with various molar ratios, prepared for calculation of the molar substitution ratio of LHSA, were analyzed by ${ }^{1} \mathrm{H}-\mathrm{NMR}$. The linear regression line was plotted by the ratio of the integration area between the SA peak (2.80 ppm) and the LMWH peak (1.95 ppm). The degree of substitution of LHSA5 was calculated to be $34.0 \%$, which indicates that approximately 1.7 of $\mathrm{SA}$ is conjugated to each LMWH (Figure S1).

The anticoagulant activities of LHSA1, LHSA3, and LHSA5 were $60.41 \%, 32.09 \%$, and $31.92 \%$, respectively, compared with that of free LMWH (Table 1). It is notable that the anticoagulant activity of LHSA5 did not significantly change with the encapsulation of DCT at 5:1 (LHSA5/DCT, w/w). 
A

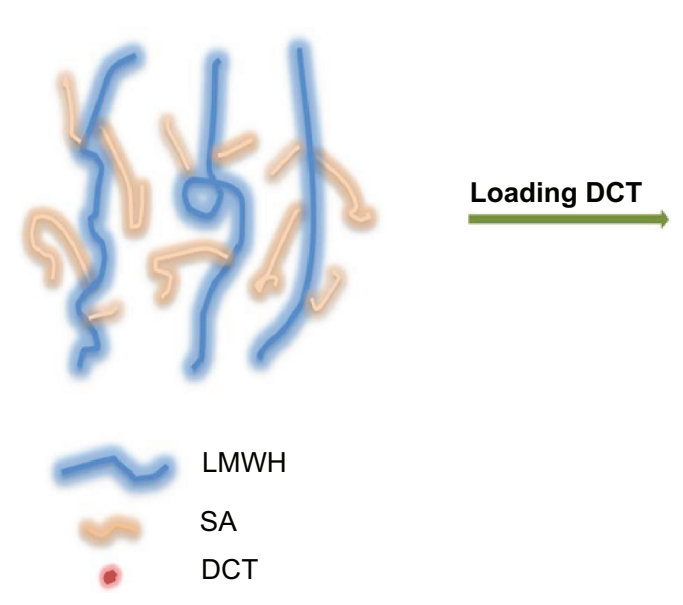

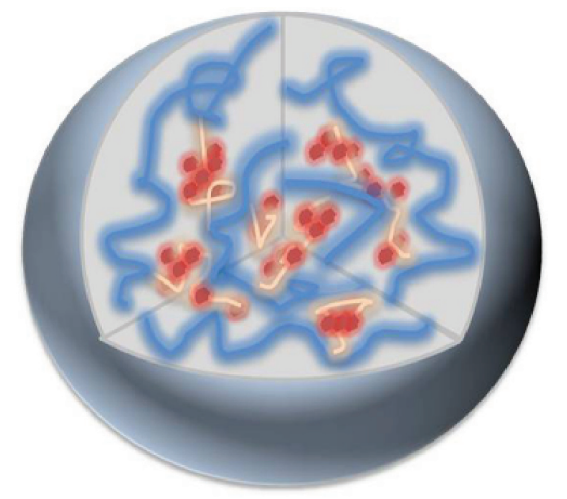

B<smiles>CCN=C=NCCC[NH2+]C</smiles>

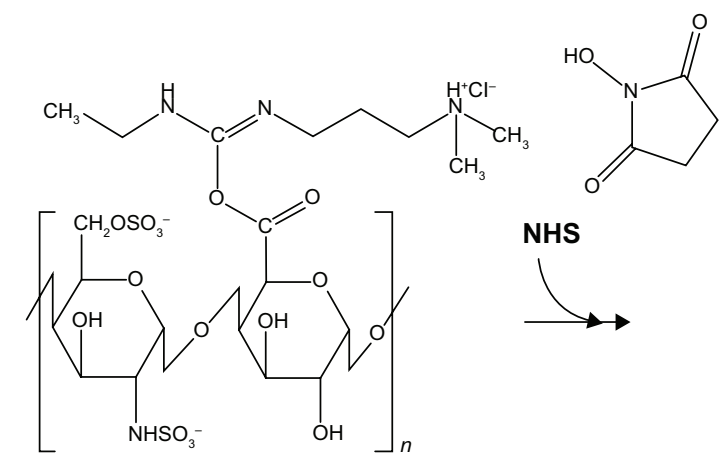

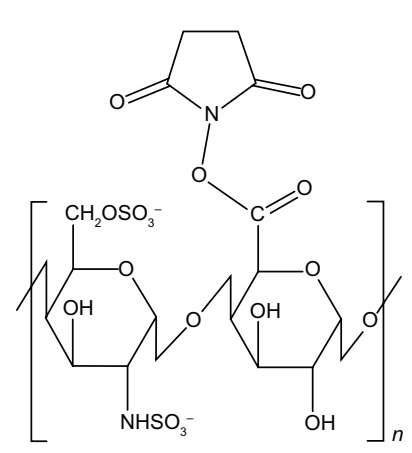

LMWH

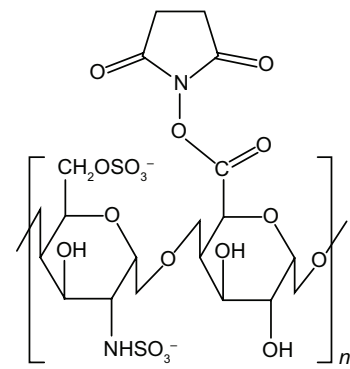

LMWH-NHS

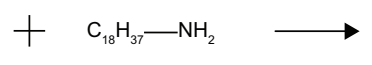

SA

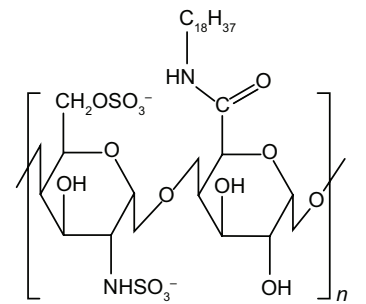

LHSA

Figure I (A) Schematic illustration of LHSA-based nanoparticles and (B) synthetic scheme for LHSA conjugates.

Abbreviations: LMWH, low-molecular-weight heparin; SA, stearylamine; DCT, docetaxel; LHSA, LMWH-SA; NHS, N-hydroxysuccinimide; EDC, I-ethyl-3-(-3-dimethylaminopropyl) carbodiimide.

\section{Preparation and characterization of LHSA-based self-assembled nanoparticles}

A solvent evaporation method was used to load DCT into the LHSA-based nanoparticles. Blank self-assembled LHSA nanoparticles were prepared without DCT loading by dissolving the LHSA conjugate in an aqueous solution. The mean diameter, zeta potential, and drug loading values are shown in Table 1. All samples successfully formed nanoparticles with a mean diameter of 140-180 nm, which was confirmed by the size distribution and TEM of LHSA nanoparticles (Figure 3A, LHSA1; Figure 3B, LHSA3; Figure 3C, LHSA5). The polydispersity index of blank and DCT-loaded nanoparticles were $0.171 \pm 0.04$ and $0.161 \pm 0.04$, respectively, indicating a narrow size distribution of the nanoparticles (Figure 3). It is interesting to note that the incorporation of DCT in the LHSA5 nanoparticles leads to a decrease of the particle size from 177.9 to $155.20 \mathrm{~nm}$ (Table 1). The loading of hydrophobic drugs in the inner core can enhance the stability of selfassembled nanoparticles by inducing morphology transition in order to decrease the total free energy, thereby resulting in the reduction of particle size..$^{38,39}$ The nanoparticles showed negative zeta potential values due to the LMWH located in the shell. The CMC of LHSA nanoparticles was determined by measuring the fluorescence intensity in the presence of pyrene as a probe. After measuring the fluorescence intensity ratio $\left(\mathrm{I}_{1} / \mathrm{I}_{3}\right)$ at various concentrations of the LHSA conjugate, 

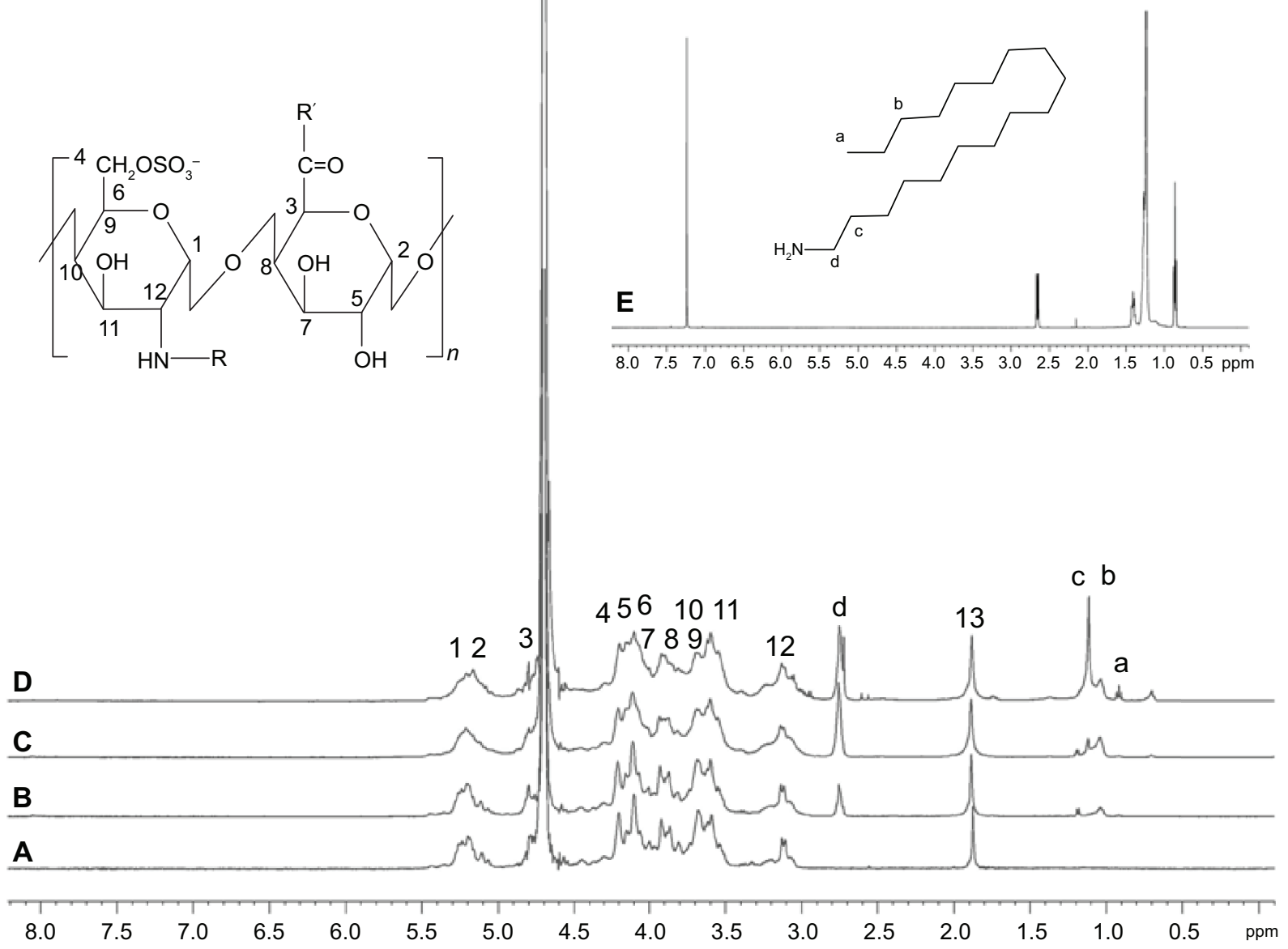

Figure 2 'H NMR spectra of (A) LMWH, (B) LHSAI, (C) LHSA3, (D) LHSA5, and (E) SA.

Notes: Samples were dissolved in $\mathrm{D}_{2} \mathrm{O}$ for ' $\mathrm{H}$ NMR analysis $\left(\mathrm{R}=-\mathrm{SO}_{3}^{-}\right.$[predominant] or $-\mathrm{COCH}_{3}\left[\right.$ peak I3]; $\left.\mathrm{R}^{\prime}=\mathrm{SA}\right)$.

Abbreviations: 'H-NMR, proton nuclear magnetic resonance; LMWH, low-molecular-weight heparin; LHSA, LMWH-SA; SA, stearylamine.

the CMC was determined from the threshold concentration of self-assembled nanoparticles (Figure 4A). The CMC value of LHSA5 was $0.044 \mathrm{mg} \mathrm{mL}^{-1}$; however, the $\mathrm{CMC}$ values for LHSA1 and LHSA3 could not be determined (Table 1). This result suggests that the LHSA5 conjugate can form more stable nanoparticulate structures in an aqueous environment, compared with LHSA1 or LHSA3.

The encapsulation efficiency and the drug loading content in the LHSA5/DCT nanoparticles was $59.82 \%$ and $10.68 \%$, respectively (Table 1). TEM images showed that the

Table I Characterization of LHSA-based nanoparticles

\begin{tabular}{|c|c|c|c|c|c|c|c|}
\hline Formulation & $\begin{array}{l}\text { Particle size } \\
(\mathrm{nm})\end{array}$ & $\begin{array}{l}\text { Polydispersity } \\
\text { index }\end{array}$ & $\begin{array}{l}\text { Zeta potential } \\
(\mathrm{mV})\end{array}$ & $\begin{array}{l}\text { Encapsulation } \\
\text { efficiency (\%) }\end{array}$ & $\begin{array}{l}\text { Drug loading } \\
\text { content (\%) }\end{array}$ & $\begin{array}{l}\text { CMC } \\
(\mathrm{mg} / \mathrm{mL})\end{array}$ & $\begin{array}{l}\text { Factor Xa } \\
(\%)\end{array}$ \\
\hline LHSAI & $146.10 \pm 8.92$ & $0.25 \pm 0.07$ & $-15.39 \pm 8.44$ & - & - & ND & 60.41 \\
\hline LHSA3 & $175.60 \pm 6.54$ & $0.23 \pm 0.08$ & $-33.92 \pm 1.34$ & - & - & ND & 32.09 \\
\hline LHSA5 & $177.90 \pm 7.22$ & $0.17 \pm 0.04$ & $-33.13 \pm 0.72$ & - & - & 0.044 & 31.92 \\
\hline LHSA5/DCT (5:I, w/w) & $155.20 \pm 3.46$ & $0.16 \pm 0.04$ & $-35.34 \pm 0.26$ & $59.82 \pm 3.86$ & $10.68 \pm 0.6 \mid$ & - & 33.48 \\
\hline
\end{tabular}

\section{Notes:}

Encapsulation efficiency $(\%)=\frac{\text { Actual amount of docetaxel in formulation }}{\text { Input amount of docetaxel in formulation }} \times 100$.

Drug loading content $(\%)=\frac{\text { Amount of docetaxel in formulation }(\mathrm{mg})}{\text { Amount of formulation }(\mathrm{mg})} \times 100$.

Abbreviations: CMC, critical micelle concentration; ND, not determined. 
A

LHSA1 nanoparticles
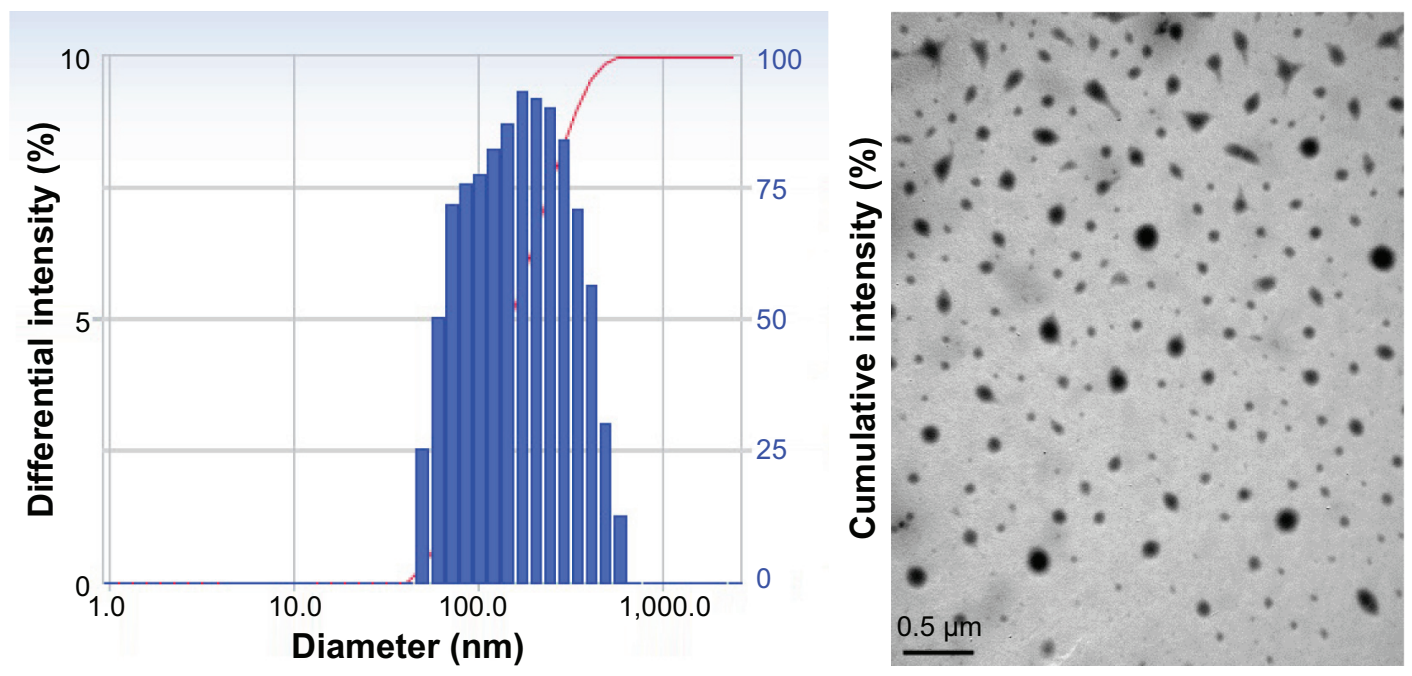

B

LHSA3 nanoparticles
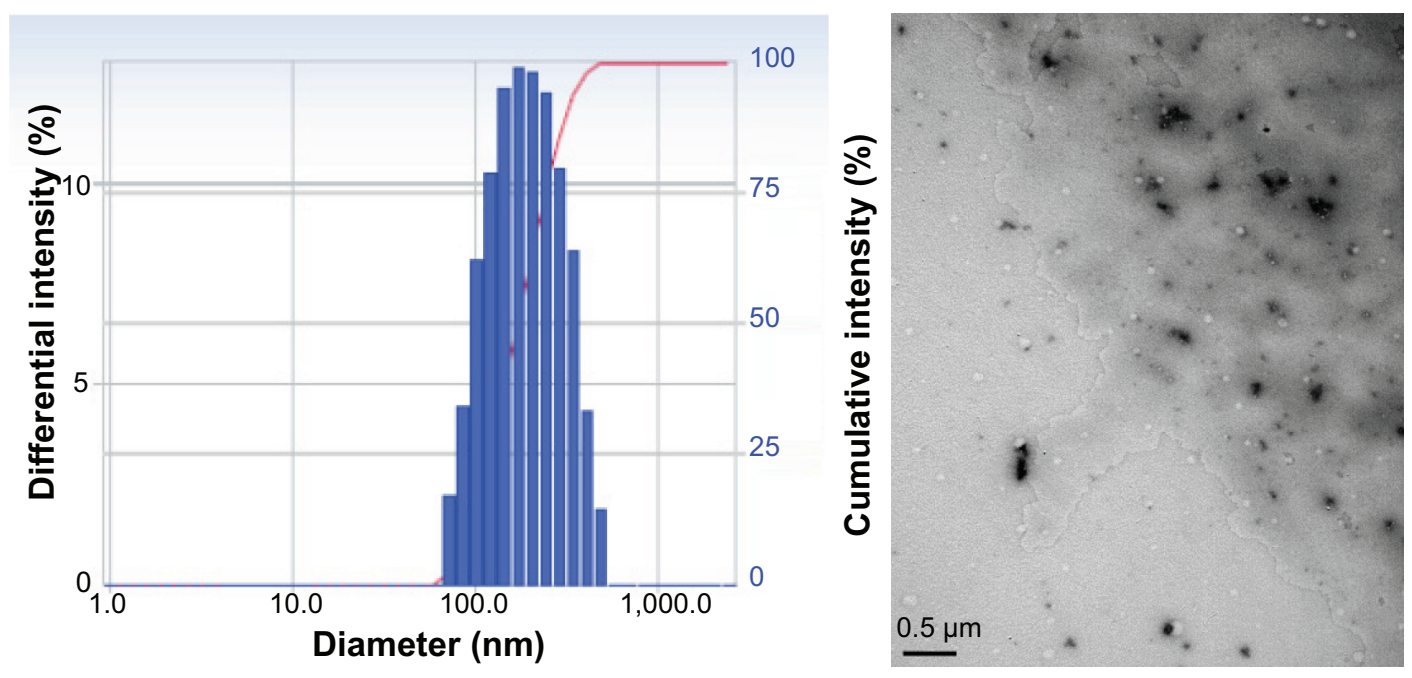

C

LHSA5 nanoparticles
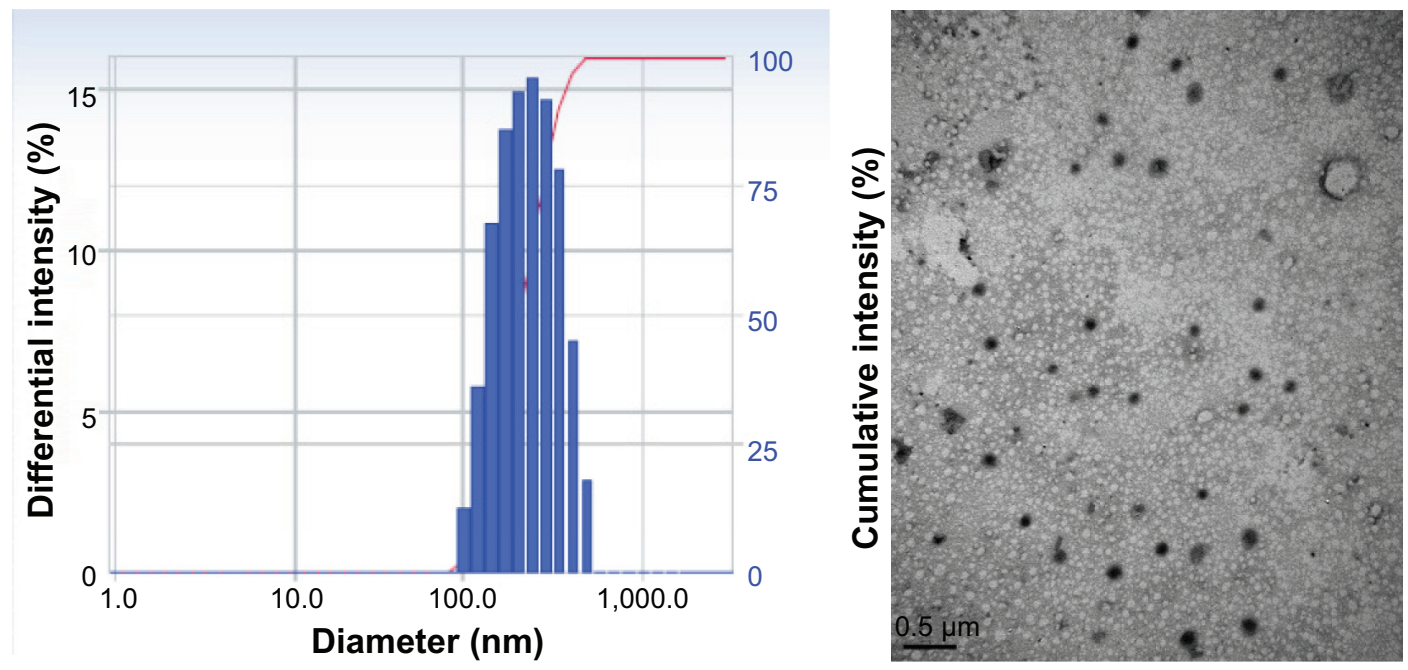

Figure 3 Size distribution and TEM images of LHSA nanoparticles.

Note: (A) LHSAI nanoparticles, (B) LHSA3 nanoparticles, (C) LHSA5 nanoparticles. The length of the scale bar in the TEM images is $500 \mathrm{~nm}(\times 200,000)$. Abbreviations: TEM, transmission electron microscopy; LHSA, LMWH-SA; LMWH, low-molecular-weight heparin; SA, stearylamine. 
A

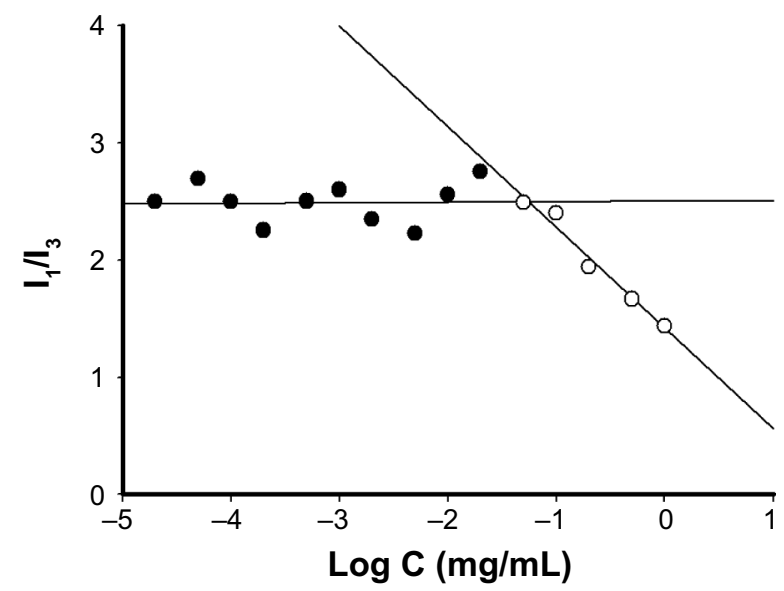

B
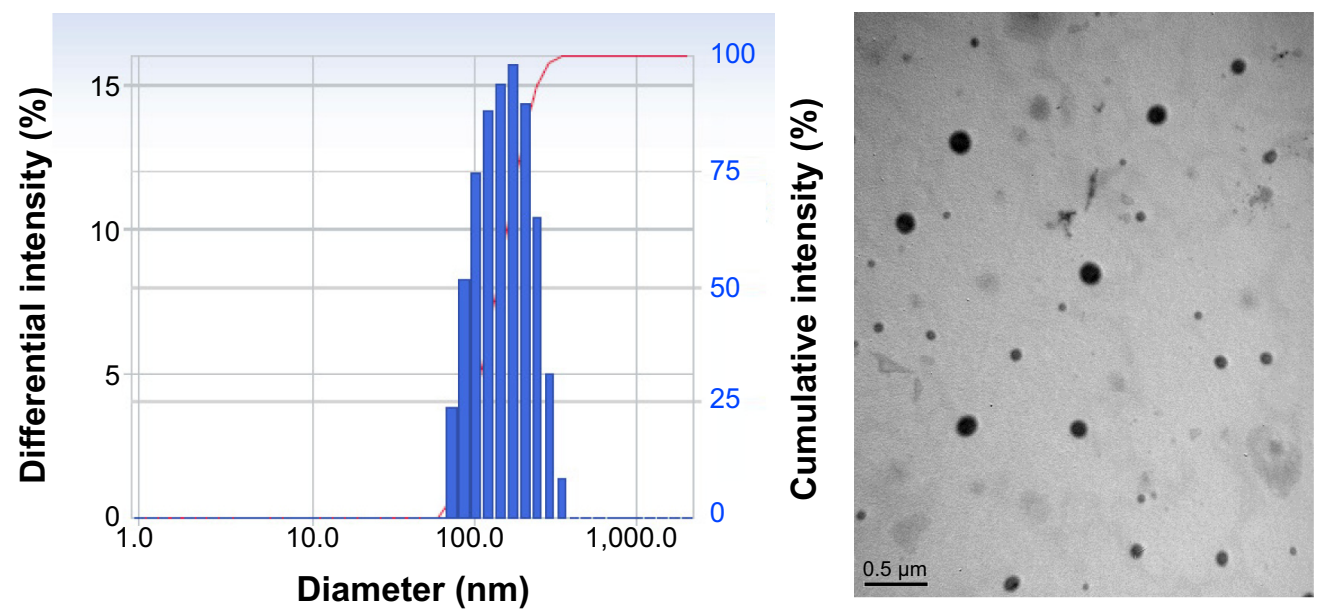

Figure 4 Characterization of DCT-loaded LHSA-based nanoparticles. (A) CMC determination of LHSA5 nanoparticles. (B) Size distribution and TEM image of DCT-loaded LHSA5 nanoparticles.

Note: The length of the scale bar in the TEM image is $500 \mathrm{~nm}(\times 200,000)$.

Abbreviations: DCT, docetaxel; LHSA, LMWH-SA; LMWH, low-molecular-weight heparin; SA, stearylamine; CMC, critical micelle concentration; TEM, transmission electron microscopy.

DCT-loaded LHSA-based nanoparticles were also spherical in shape with narrow size distribution (Figure 4B).

\section{In vitro DCT release}

Figure 5 shows the in vitro DCT release profile. DCT was incorporated in the LHSA5 nanoparticles and the sink condition was adequately maintained in the release test. The in vitro release of DCT from LHSA5 nanoparticles was investigated for 6 days. After the initial release for 24 hours, the release rate of DCT slightly decreased with incubation time, and showed a sustained DCT release pattern. The release level of DCT within 24 hours was 48.24\%; additional release continued up to 96 hours. A sustained DCT release pattern can lead to reduction in in vivo drug clearance, which results in maintenance of adequate drug concentrations for tumor growth inhibition.

\section{In vitro cytotoxicity of LHSA conjugate}

The cytotoxicity of blank LHSA5 conjugate was investigated in MCF-7 (Figure 6A) and MDAMB 231 (Figure 6B) breast cancer cell lines. Cell viability was measured after treating with various concentrations of LMWH and blank LHSA5 conjugate for 24 hours. At all blank LHSA5 conjugate polymer concentrations $\left(0-200 \mu \mathrm{g} \mathrm{mL} \mathrm{L}^{-1}\right)$, no significant viability differences between the LMWH and blank LHSA5 conjugate groups were observed, indicating that the blank LHSA5 conjugate polymer exerted no severe cytotoxicity on MCF-6 and MDAMB 231 cells.

\section{In vitro antitumor effect}

In vitro antitumor effects were evaluated using MCF-7 (Figure 7A) and MDAMB 231 (Figure 7B) cells. Free DCT (Taxotere) and DCT-loaded LHSA5 nanoparticles 


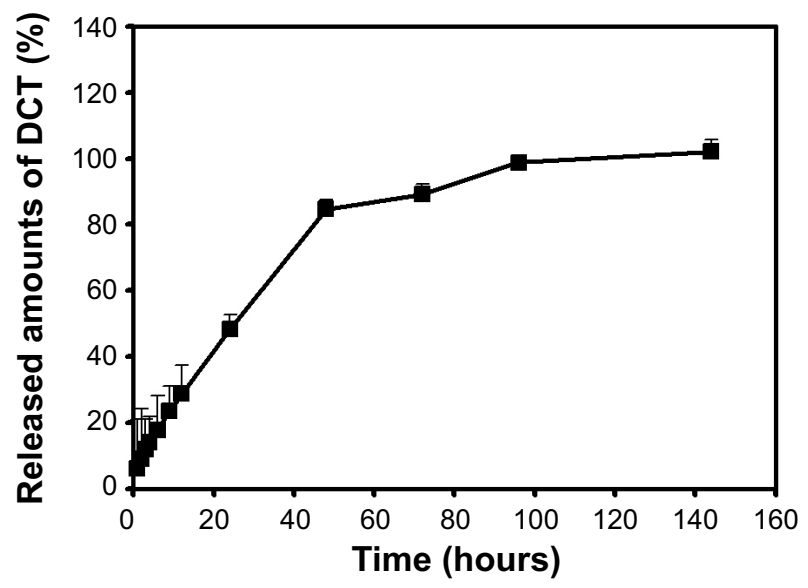

Figure $\mathbf{5}$ In vitro release profile of DCT from LHSA5-based nanoparticles. Note: Each point represents mean \pm SD $(n=3)$.

Abbreviations: DCT, docetaxel; LHSA, LMWH-SA; LMWH, low-molecular-weight heparin; SA, stearylamine; SD, standard deviation.

have antitumor efficacy against MCF-7 and MDAMB 231 cells. The DCT-loaded LHSA5 nanoparticle exhibited a similar or slightly lower efficacy than free DCT, possibly due to sustained release of free DCT from LHSA5 nanoparticles.

\section{In vitro cellular uptake study}

MCF-7 and MDAMB 231 cells are human breast cancer cell lines, and were selected since DCT is mainly used for the treatment of breast cancer. ${ }^{40}$ To investigate the cellular uptake efficiency of LHSA5 nanoparticles, LHSA5 nanoparticles loaded with C6 were observed using CLSM, with 4',6diamidino-2-phenylindole staining of nuclei in MCF-7 and MDAMB 231 cells. C6 is a fluorescence probe that has been widely used in cellular uptake studies of nanoparticles. ${ }^{34,41}$ In Figure 8A, the stronger green fluorescent signals indicate higher intracellular accumulation of C6 from LHSA5 nanoparticles compared to that from the $\mathrm{C} 6$ solution.

Cellular uptake efficiency was also quantitatively determined in MCF-7 (Figure S2A) and MDAMB 231 cells (Figure S2B) by a flow cytometry. The fluorescence intensity was assumed to be proportional to the amount of C6 in the cells; however, fluorescence was barely detected in the control (no treatment) and blank nanoparticle groups. Figure $8 \mathrm{~B}$ shows that significantly higher amounts of $\mathrm{C} 6$ from LHSA5-based nanoparticles were taken up by the cells, compared with the C6 solution, which is consistent with the results of the CLSM study (Figure 8A). This result can be explained by the endocytosis of the nanoparticles. ${ }^{42,43}$ A previous study showed that fatty acid-modified polysaccharidebased nanoparticles form self-assembled nanoparticles with a multihydrophobic core. ${ }^{44}$ A hydrophobic minor core could facilitate the internalization of nanoparticles into cells via interaction with the plasma membrane. Although LHSA5based nanoparticles are negatively charged due to their many sulfate and carboxyl groups, the nanoparticle was taken up in higher amounts, compared with the C6 solution.

\section{In vivo antitumor efficacy}

In vivo antitumor efficacy of the DCT-loaded LHSA5 nanoparticle formulation was evaluated in the MDAMB 231 tumor-bearing mouse model. Blank LHSA5 nanoparticles, DCT solution (Taxotere), and DCT-loaded LHSA5 nanoparticles were injected intravenously on days 0,7 , and 14 . Then, tumor volume $\left(\mathrm{mm}^{3}\right)$ and body weight $(\mathrm{g})$ were monitored for 18 days.

The tumor volumes of the blank LHSA5 nanoparticletreated, DCT solution (Taxotere)-treated, and DCT-loaded
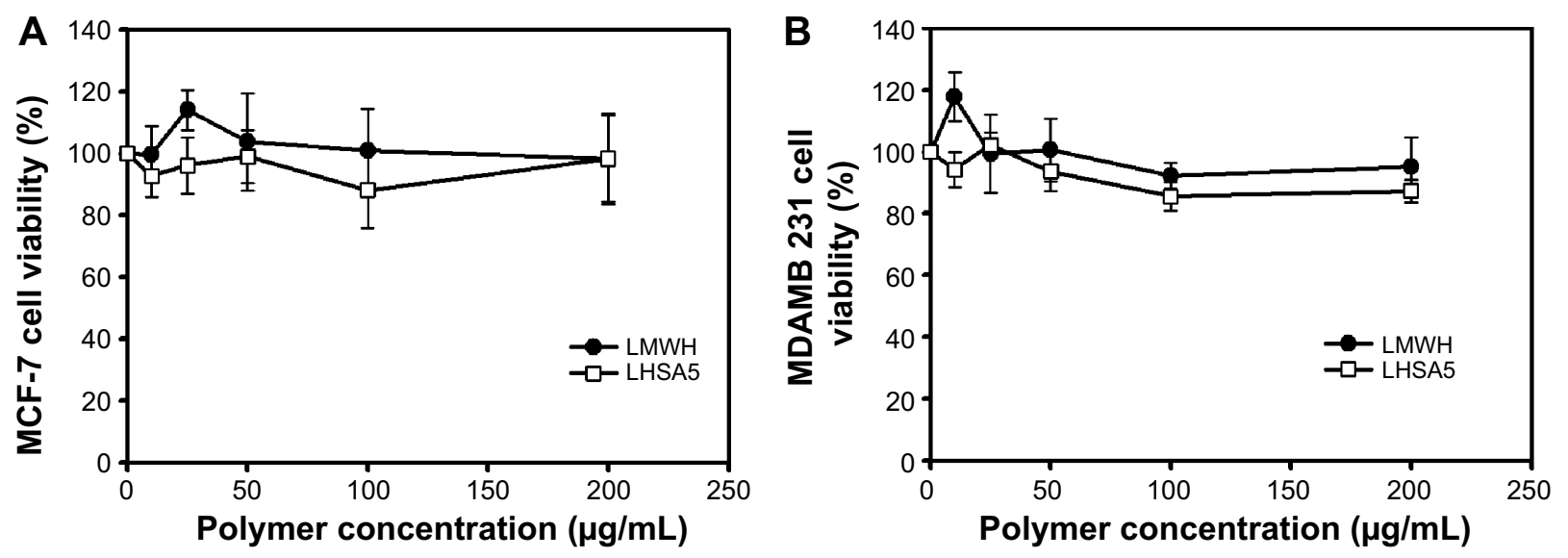

Figure 6 In vitro cytotoxicity of LHSA5 in (A) MCF-7 and (B) MDAMB 23I cells.

Notes: Cell viability was measured by MTS-based assay after incubating LMWH or LHSA5 at various polymer concentrations for 24 hours. Data are presented as mean \pm $\mathrm{SD}(\mathrm{n}=5)$.

Abbreviations: LMWH, low-molecular-weight heparin; LHSA, LMWH-SA; LMWH, low-molecular-weight heparin; SA, stearylamine; SD, standard deviation. 

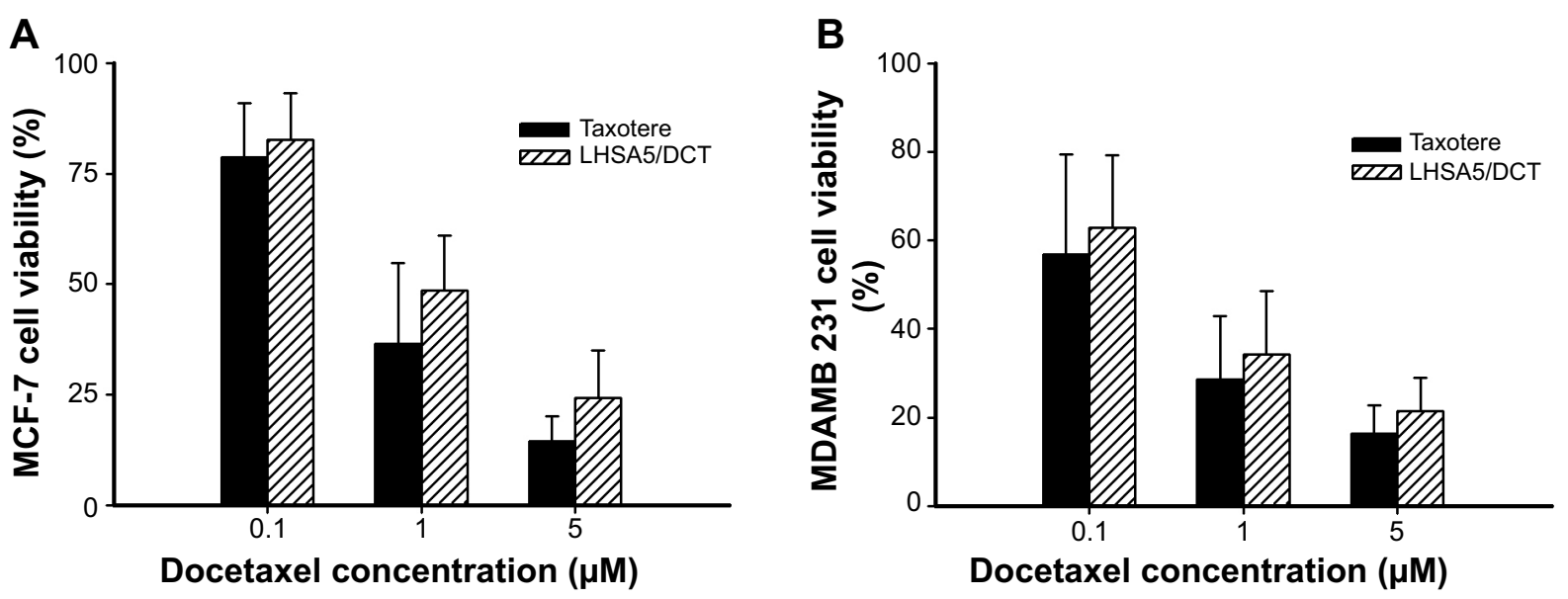

Figure 7 In vitro antitumor efficacy of Taxotere and DCT-loaded LHSA5 nanoparticles in (A) MCF-7 and (B) MDAMB 23I cells. Abbreviations: LHSA, LMWH-SA; LMWH, low-molecular-weight heparin; SA, stearylamine; DCT, docetaxel.

A

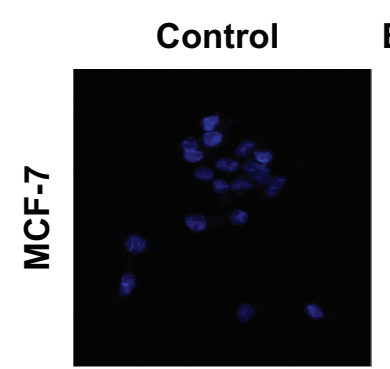

\section{Blank nanoparticles}
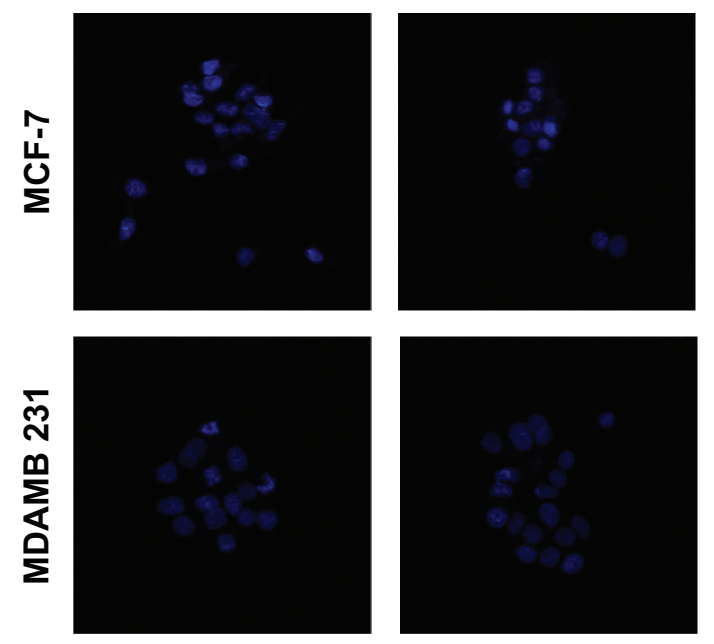
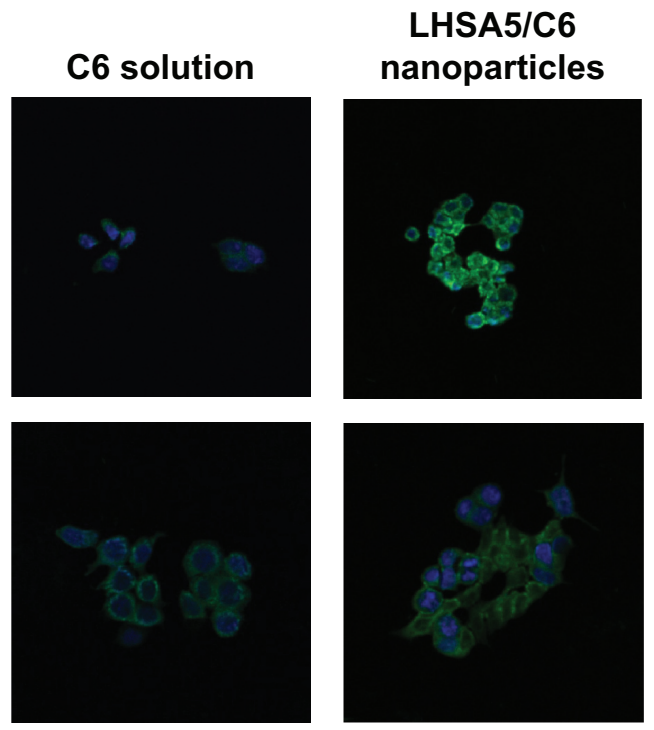

B
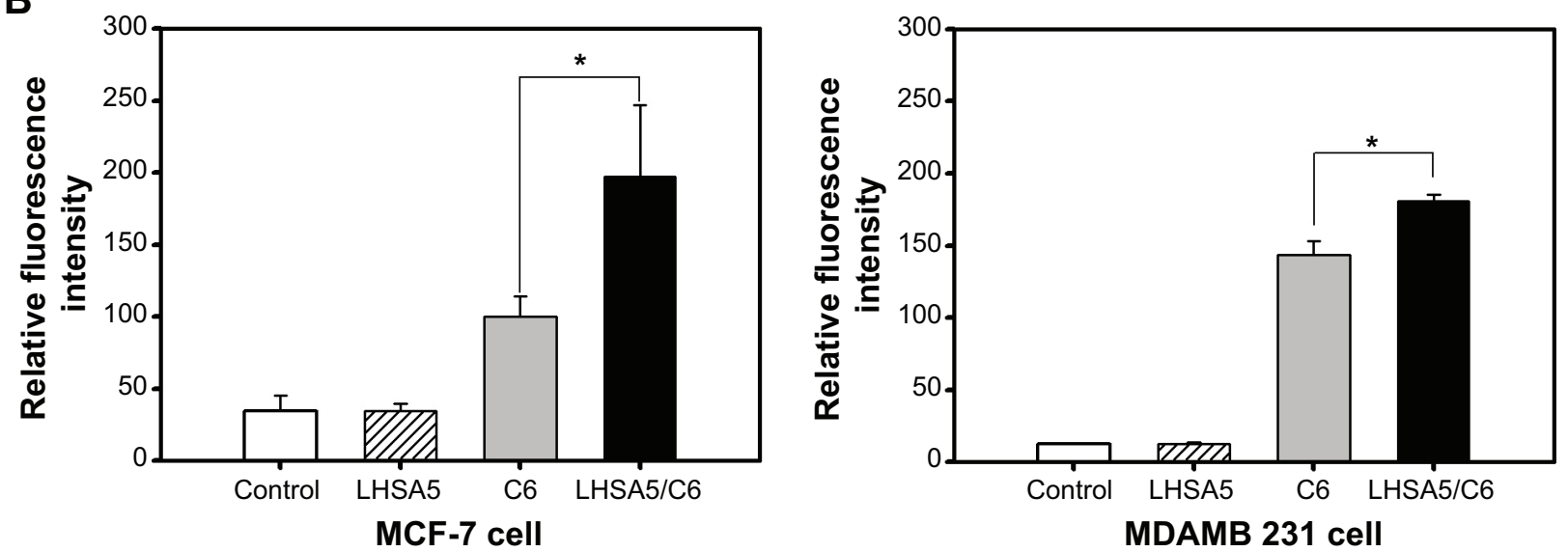

Figure 8 In vitro cellular uptake of coumarin 6

Notes: The cellular uptake was observed by (A) CLSM and (B) FACS in MCF-7 and MDAMB 23 I cells after incubating for 2 hours. Merged images composed of coumarin 6 (green color) and DAPI (blue color) are shown. Groups were as follows: control, blank LHSA5 nanoparticles, coumarin 6 solution, coumarin 6 -loaded LHSA5 nanoparticles. $* P<0.05$, between two groups.

Abbreviations: FACS, fluorescence-activated cell sorter; CLSM, confocal laser scanning microscope; LHSA, LMWH-SA; LMWH, low-molecular-weight heparin; SA, stearylamine. 

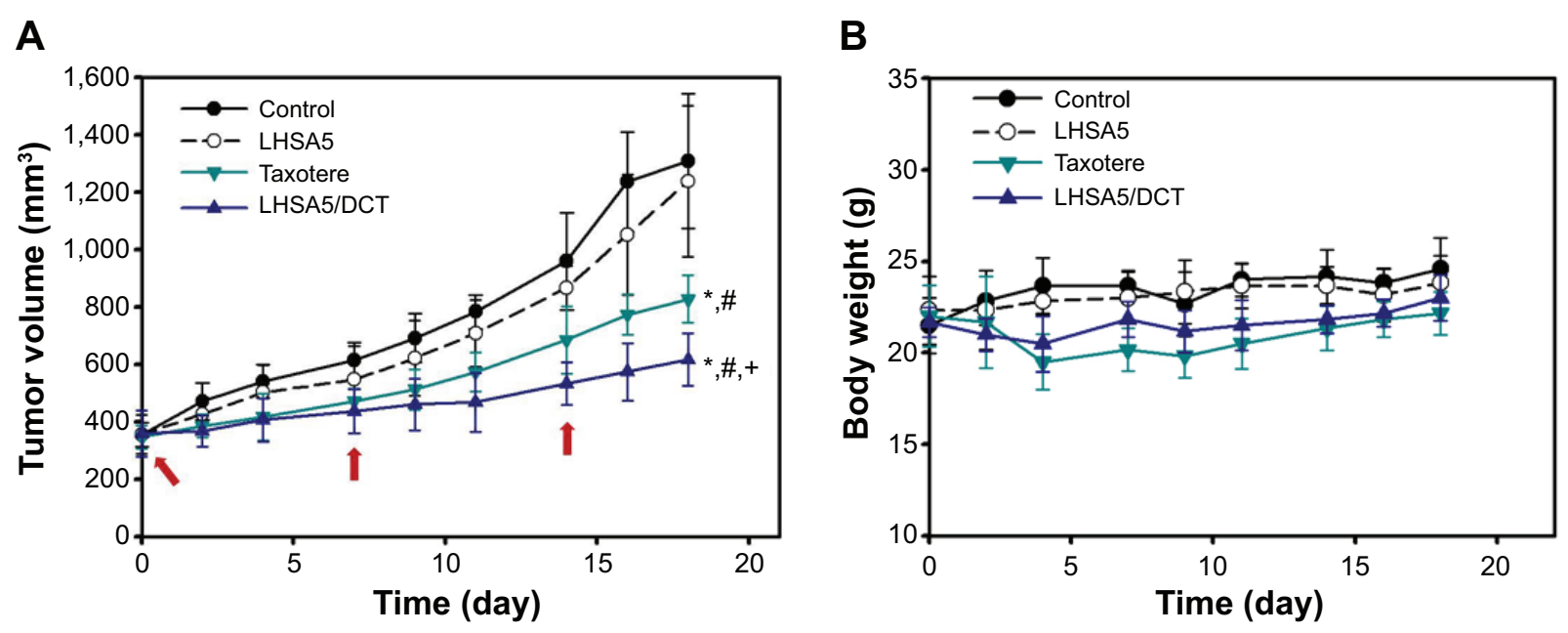

Figure 9 In vivo antitumor efficacy in the MDAMB 23I tumor-bearing mouse model.

Notes: (A) Tumor volume $\left(\mathrm{mm}^{3}\right)$ profiles according to time (day) are shown. All samples were injected on day 0,7 , and I4 (red arrows). Points indicate the means \pm SD $(n=5)$. (B) Body weight $(g)$ was also measured with tumor size measurement for 18 days. Points indicate the means $\pm S D$ ( $n=5$ ). $* P<0.05$ compared with the control group; ${ }^{\#} P<0.05$ compared with the LHSA5 group; ${ }^{+} P<0.05$ compared with the Taxotere group.

Abbreviations: LHSA, LMWH-SA; LMWH, low-molecular-weight heparin; SA, stearylamine; DCT, deocetaxel; SD, standard deviation.

LHSA5 nanoparticle-treated groups on day 18 were $94.6 \%$, $63.2 \%$, and $47.1 \%$ that of the control group, respectively (Figure 9A). The most effective inhibition of tumor growth was observed in the group treated with DCT-loaded LHSA5 nanoparticles, while the blank LHSA5 nanoparticle treatment had little effect on tumor growth inhibition. Moreover, the tumor growth inhibition effect of the DCT-loaded LHSA5 nanoparticles was significantly greater than that of Taxotere $(P<0.05)$.

The safety of DCT-loaded LHSA nanoparticles was evaluated by measuring changes in body weight. For most groups, there was no significant difference in body weight (Figure 9B). However, the body weight of the Taxoteretreated group was significantly lower than that of the control group. The DCT-loaded LHSA5 nanoparticle-treated group showed no significant difference compared with the control group, suggesting that the DCT-loaded LHSA nanoparticle treatment was less toxic than Taxotere.

\section{In vivo pharmacokinetic study}

Figure 10 shows the plasma concentration-time profiles of DCT solution (Taxotere) and DCT-loaded LHSA5 nanoparticles, at a dose of $8 \mathrm{mg} \mathrm{kg}^{-1}$, in Sprague Dawley rats; relevant pharmacokinetic parameters are listed in Table 2. Our results showed that DCT was rapidly eliminated from the bloodstream in both the Taxotere and LHSA5 nanoparticle groups over the first 30 minutes after dosing. However, after dose normalization, the DCT in LHSA5 nanoparticles yielded a higher plasma concentration than did Taxotere. Noncompartmental analysis of the plasma concentrations showed a significant change in the pharmacokinetic parameters of DCT in LHSA5 nanoparticles. Compared with Taxotere, the LHSA5 nanoparticles provided a significantly higher AUC (2.48-fold), terminal $t_{1 / 2}$ (3.02-fold), and mean residence time (3.64-fold). The LHSA5 nanoparticles also significantly decreased the clearance (CL, 2.54-fold) of DCT. These in vivo pharmacokinetic properties were thought to be related to its in vitro sustained release pattern. This result indicates that the LHSA5 nanoparticles prolonged the circulation of DCT in the bloodstream, thereby improving its therapeutic efficacy (Figure 9A).

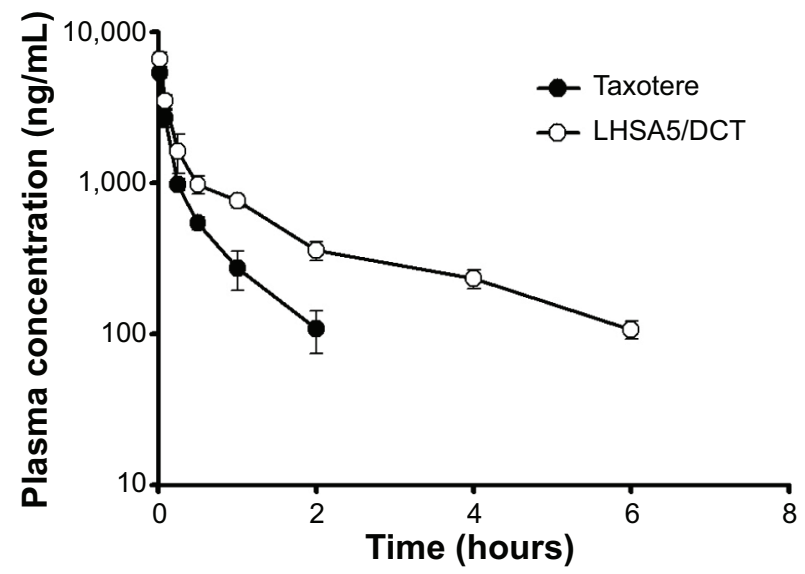

Figure 10 In vivo pharmacokinetic profile.

Notes: The pharmacokinetic profile was studied after intravenous injection of Taxotere and DCT-loaded LHSA5 nanoparticle formulation in rats at a dose of $8 \mathrm{mg} / \mathrm{kg}$ DCT. Points represent the mean \pm SD $(n=4)$.

Abbreviations: DCT, docetaxel; LHSA, LMWH-SA; LMWH, low-molecular-weight heparin; SA, stearylamine; SD, standard deviation. 
Table 2 Pharmacokinetic parameters of Taxotere and DCTloaded LHSA5 nanoparticles after a single intravenous injection $(8 \mathrm{mg} / \mathrm{kg})$ in rats $(\mathrm{n}=4)$

\begin{tabular}{lll}
\hline Parameter & Taxotere & LHSA5/DCT \\
\hline AUC $(\mu \mathrm{g} \mathrm{min} / \mathrm{mL})$ & $75.075 \pm 10.19 \mid$ & $\mid 86.767 \pm 24.62 I^{*}$ \\
Terminal $t_{1 / 2}(\mathrm{~min})$ & $38.024 \pm 6.265$ & $|2| .789 \pm 11.805^{*}$ \\
$\mathrm{CL}(\mathrm{mL} / \mathrm{min} / \mathrm{kg})$ & $100.374 \pm 15.558$ & $39.44 I \pm 4.999 *$ \\
$V_{\mathrm{ss}}(\mathrm{mL} / \mathrm{kg})$ & $5,401.316 \pm|3| .480$ & $6,910.463 \pm 979.348$ \\
MRT $(\mathrm{min})$ & $23.466 \pm 2.227$ & $85.432 \pm 4.043^{*}$ \\
\hline
\end{tabular}

Notes: Data presented as mean $\pm S D(n=4) * P<0.05$ compared with Taxotere group. Abbreviations: DCT, docetaxel; LHSA, LMWH-SA; LMWH, low-molecular-weight heparin; SA, stearylamine; AUC, total area under the plasma concentration-time curve from time zero to the end time point; $\mathrm{CL}$, time-averaged total body clearance $V_{\mathrm{ss}}$, the apparent volume of the distribution under steady-state conditions; MRT, the mean residence time; SD, standard deviation.

\section{Discussion}

The synthetic scheme for the amphiphilic LHSA conjugate is shown in Figure 1. Amphiphilic LHSA conjugates with various LMWH to SA molar ratios were synthesized to investigate the feasibility of forming stable self-assembled nanoparticles. From ${ }^{1} \mathrm{H}-\mathrm{NMR}$ analysis of LHSA conjugates, the proton peak of SA (chemical shifts at 0.8-1.2 ppm) in LHSA1 and LHSA3 was lower than that for LHSA5 (Figure 2). An accurate substitution ratio (SA to LMWH) can be determined from the ${ }^{1} \mathrm{H}-\mathrm{NMR}$ spectrum of the physical mixtures of LMWH and SA. In our previous study, ${ }^{45}$ the correlation of the molar ratio of arachidic acid to chitosan oligosaccharide (CSO) was evaluated using ${ }^{1} \mathrm{H}-\mathrm{NMR}$ from a physical mixture of arachidic acid and CSO in DMSO-d ${ }_{6}$. However, LMWH has a strong hydrophilic property, while SA has a strong hydrophobic property; thus, an NMR cosolvent consisting of $\mathrm{D}_{2} \mathrm{O}$ and THF- $\mathrm{d}_{8}$ was used to dissolve LMWH and SA. The molar substitution ratios increased with increasing feed SA molar ratio. Note that these results are contrary to those of the anticoagulant activity of LHSA conjugates calculated using an anti-FXa chromogenic assay (Table 1); the anticoagulant activity of LHSA conjugates decreased as the amount of chemically coupled SA increased (Table 1), which is consistent with previously reported heparin derivative studies. ${ }^{46,47}$

All LHSA1, LHSA3, and LHSA5 conjugates prepared in this study formed self-assembled nanoparticles that were $140-180 \mathrm{~nm}$ in size. It is known that nanoparticles with a mean diameter $<200 \mathrm{~nm}$ accumulate in tumors via the enhanced permeability and retention effect and exhibit reduced uptake by the reticuloendothelial system. ${ }^{3,48}$ Among them, the LHSA5 nanoparticles showed a narrower size distribution and a more stable spherical morphology than the LHSA1 and LHSA3 nanoparticles, as shown in Figure 3. However, the LHSA1 and LHSA3 conjugates did not possess the hydrophobicity necessary for the formation of stable nanoparticles due to the low substitution ratio of SA. Additionally, the CMC value of the LHSA5 conjugate was significantly lower $\left(44 \mu \mathrm{g} \mathrm{mL}^{-1}\right)$ than those of other lowmolecular-weight surfactants or amphiphilic polymers, ${ }^{49,50}$ indicating that it can form stable nanoparticle structures, even in the presence of the reduced polymer concentrations after dilution with body fluids.

The LMWH of LHSA creates a hydrophilic outer shell of the nanoparticles in an aqueous environment. The SA of LHSA provides an internal hydrophobic core that can be used to encapsulate insoluble drugs. ${ }^{51}$ It was interesting to note that the zeta potential values of LHSA nanoparticles were negative, indicating that the LMWH was located on the surface of the shell. Therefore, LHSA could possess heparin activity after nanoparticle formation, yet the anticoagulant activity of LHSA was lower than that of the unmodified LMWH. Because LMWH reduces the risk of embolic events in patients with malignancy and acute venous thromboembolism, ${ }^{52}$ its use in cancer patients is recommended by numerous guidelines and is now regarded as a standard of care. ${ }^{53}$ Thus, the self-assembled LHSA5 nanoparticle could be attractive as an anticancer drug carrier, which has a synergic effect with poorly water-soluble anticancer drugs encapsulated in the core.

After characterization of the blank LHSA-based nanoparticles, we evaluated the DCT-loaded LHSA nanoparticles using the LHSA5 conjugate, due to its more stable nanoparticle configuration compared with the other structures. The encapsulation efficacy of the DCT-loaded LHSA5 nanoparticle was $59.82 \%$, with TEM images revealing a spherical shape. The in vitro release of DCT from the LHSA5 nanoparticle continued for $\sim 96$ hours, as shown in Figure 5. From these results, we expected a reduction in the in vivo drug clearance, allowing a drug concentration adequate for tumor growth inhibition to be sustained. When intravenously administered in Sprague Dawley rats, the concentration profile of DCT in plasma was sustained for 6 hours, as compared with 2 hours for Taxotere administration (Figure 10).

The effects of the DCT-loaded LHSA5 nanoparticles on in vitro cytotoxicity and antitumor efficacy in MCF-7 and MDAMB 231 cells were investigated, as shown in Figures 6 and 7. The LMWH and blank LHSA5 nanoparticles exhibited no severe in vitro cytotoxicity. Free DCT and DCTloaded LHSA5 nanoparticles were cytotoxic to MCF-7 and MDAMB 231 cells. DCT-loaded LHSA5 nanoparticles had a similar or slightly lower efficacy than free DCT, thus contributing to the sustained release of free DCT from LHSA5 
nanoparticles. As shown in Figure 5, only $40 \%$ of the free DCT was released from LHSA5 nanoparticles in 24 hours in the in vitro release study.

C6 has been widely used in cellular uptake studies, ${ }^{34,41}$ and was used in this study as a fluorescence probe to investigate the cellular uptake efficiency of the LHSA nanoparticle. LHSA5 nanoparticles loaded with $\mathrm{C} 6$ in MCF-7 and MDAMB 231 cells were visualized by CLSM (Figure 8A). A significant difference was observed in the fluorescence intensities of the C6 solution and the C6-loaded LHSA nanoparticles. In addition, a significantly higher amount of C6 from the LHSA5 nanoparticle was taken up by the cells compared to that from the $\mathrm{C} 6$ solution, as shown in Figure $8 \mathrm{~B}$. This result could be attributable to endocytosis of the nanoparticles. ${ }^{42,43}$ Moreover, the fatty acid-modified polysaccharide-based nanoparticles are capable of forming self-assembled nanoparticles with a multihydrophobic core. ${ }^{44}$ The hydrophobic part of the nanoparticles could facilitate drug internalization into the cells via interactions with the cell membrane. Although the LHSA5-based nanoparticles were negatively charged due to their sulfate and carboxyl groups, the nanoparticles were taken up in significantly higher amounts compared with the C6 solution. In addition to drug uptake by nanoparticles, long-term cellular drug retention can play key roles in drug efficacy in microtubule-targeted anticancer drugs. ${ }^{54}$ Thus, LHSA5 nanoparticles could induce a synergy effect by enhancing drug uptake and retention time, which are shown in in vivo antitumor efficacy study (Figure 9).

The DCT-loaded LHSA5 nanoparticles exhibited significant inhibitory effects on MDAMB 231 tumor growth, compared with the other groups (Figure 9A). This can be explained in terms of the physicochemical properties of the drug-loaded nanoparticles that induce sustained drug release (Figure 10) and passive targeting to tumor tissue via an enhanced permeability and retention effect. Although the blank LHSA5 nanoparticles showed insignificant in vivo inhibition of MDAMB 231 tumor growth in this study, others have reported the antitumor effects of several heparin derivatives in tumor-bearing mice. ${ }^{36,55,56}$ This discrepancy can be attributed to the differences in tumor type, heparin injection frequency and capacity, administration route, and heparin-modifying molecules.

The concentration profile of DCT in plasma was sustained up to 6 hours (Figure 10). This result indicates that LHSA5 nanoparticles contributed to prolonged circulation of DCT in the bloodstream and is consistent with the improved therapeutic efficacy (Figure 9A). Compared with the DCT solution, the DCT-loaded LHSA5 nanoparticles provided a significantly higher $\mathrm{AUC}, t_{1 / 2}$, and mean residence time and a lower time-averaged total body clearance, as shown in Table 2. These in vivo pharmacokinetic parameters were related to its in vitro sustained DCT release pattern. Moreover, the increased retention time and decreased clearance of the DCT from plasma may contribute to enhanced in vivo antitumor efficacy in the tumor xenograft model, as shown in Figure 9A.

\section{Conclusion}

LHSA conjugates were successfully synthesized, and selfassembled nanoparticles based on LHSA were prepared. The LHSA-based nanoparticles have an LMWH moiety on the outer shell resulting in a negative surface charge. Among the synthesized conjugates, LHSA5 formed stable self-assembled nanoparticles in an aqueous environment, with a narrow size distribution. Because the LHSA5 nanoparticles showed $30 \%$ of the anticoagulant activity exhibited by free LMWH, it likely also maintains the other heparin activities. The DCT-loaded LHSA5 nanoparticle showed sustained drug-release profiles, in vitro and in vivo, compared with Taxotere. The nanoparticulate structure influenced cellular uptake; consequently, the DCT-loaded LHSA5 nanoparticle formulation improved the half-life of DCT and significantly inhibited MDAMB 231 tumor growth in xenograft mice. Thus, LHSA5-based selfassembled nanoparticles may be useful as an anticancer drug delivery system.

\section{Acknowledgments}

This work was supported by the National Research Foundation of Korea (NRF) grant funded by the Korean government (MSIP) (Number 2009-0083533) and the MarineBio Research Program (NRF-C1ABA001-20110018561).

\section{Disclosure}

The authors report no conflicts of interest in this work.

\section{References}

1. Kwon GS, Okano T. Polymeric micelles as new drug carriers. Adv Drug Deliv Rev. 1996;21(2):107-116.

2. Liu Z, Jiao Y, Wang Y, et al. Polysaccharides-based nanoparticles as drug delivery systems. Adv Drug Deliv Rev. 2008;60(15):1650-1662.

3. Maeda H, Wu J, Sawa T, et al. Tumor vascular permeability and the EPR effect in macromolecular therapeutics: a review. J Control Release. 2000; 65(1):271-284. 
4. Maeda H. Tumor-selective delivery of macromolecular drugs via the EPR effect: background and future prospects. Bioconjugate Chem. 2010; 21(5):797-802.

5. Verrecchia T, Spenlehauer G, Bazile D, et al. Non-stealth (poly(lactic acid/ albumin)) and stealth (poly(lactic acid-polyethylene glycol)) nanoparticles as injectable drug carriers. J Control Release. 1995;36(1):49-61.

6. Shao X, Liu Q, Zhang C, et al. Concanavalin A-conjugated poly(ethylene glycol)-poly(lactic acid) nanoparticles for intranasal drug delivery to the cervical lymph nodes. J Microencapsul. 2013;30(8):780-786.

7. Labhasetwar V, Song C, Humphrey W, et al. Arterial uptake of biodegradable nanoparticles: effect of surface modifications. J Pharm Sci. 1998; 87(10):1229-1234.

8. Molpeceres J, Guzman M, Aberturas MR, et al. Application of central composite designs to the preparation of polycaprolactone nanoparticles by solvent displacement. J Pharm Sci. 1996;85(2):206-213.

9. Aishwarya S, Mahalakshmi S, Sehgal PK. Collagen-coated polycaprolactone microparticles as a controlled drug delivery system. $J$ Microencapsul. 2008;25(5):298-306.

10. Sharma S, Benson HA, Mukkur TK, et al. Preliminary studies on the development of IgA-loaded chitosan-dextran sulphate nanoparticles as a potential nasal delivery system for protein antigens. J Microencapsul. 2013;30(3):283-294.

11. Jahanshahi M, Babaei Z. Protein nanoparticle: a unique system as drug delivery vehicles. Afr J Biotechnol. 2008;7(25):4926-4934.

12. Wu Y, MacKay JA, McDaniel JR, et al. Fabrication of elastin-like polypeptide nanoparticles for drug delivery by electrospraying. Biomacromolecules. 2008;10(1):19-24.

13. Kwon GS, Okano T. Soluble self-assembled block copolymers for drug delivery. Pharm Res. 1999;16(5):597-600.

14. Saravanakumar G, Min KH, Min DS, et al. Hydrotropic oligomerconjugated glycol chitosan as a carrier of paclitaxel: synthesis, characterization, and in vivo biodistribution. J Control Release. 2009;140(3): 210-217.

15. Sun P, Zhang Y, Shi L, et al. Thermosensitive nanoparticles selfassembled from PCL-b-PEO-b-PNIPAAm triblock copolymers and their potential for controlled drug release. Macromol Biosci. 2010;10(6): 621-631.

16. Lyseng-Williamson KA, Fenton C. Docetaxel. Drugs. 2005;65(17): 2513-2531.

17. Baker SD, Sparreboom A, Verweij J. Clinical pharmacokinetics of docetaxel. Clin Pharmacokinet. 2006;45(3):235-252.

18. Michael A, Syrigos K, Pandha H. Prostate cancer chemotherapy in the era of targeted therapy. Prostate Cancer Prostatic Dis. 2008;12(1): 13-16.

19. Persohn E, Canta A, Schoepfer S, et al. Morphological and morphometric analysis of paclitaxel and docetaxel-induced peripheral neuropathy in rats. Eur J Cancer. 2005;41(10):1460-1466.

20. Engels FK, Mathot RA, Verweij J. Alternative drug formulations of docetaxel: a review. Anticancer Drugs. 2007;18(2):95-103.

21. Immordino ML, Brusa $P$, Arpicco $S$, et al. Preparation, characterization, cytotoxicity and pharmacokinetics of liposomes containing docetaxel. J Control Release. 2003;91(3):417-429.

22. Yin Y-M, Cui F-D, Mu C-F, et al. Docetaxel microemulsion for enhanced oral bioavailability: preparation and in vitro and in vivo evaluation. J Control Release. 2009;140(2):86-94.

23. Esmaeili F, Dinarvand R, Ghahremani MH, et al. Docetaxel-albumin conjugates: preparation, in vitro evaluation and biodistribution studies. J Pharm Sci. 2009;98(8):2718-2730.

24. Buller H, Gent M, Gallus A, et al. Low-molecular weight heparin in the treatment of patients with venous thromboembolism: the Columbus Investigators. N Engl J Med. 1997;337:657-662.

25. Young E. The anti-inflammatory effects of heparin and related compounds. Thromb Res. 2008;122(6):743-752.

26. Niers TMH, Klerk CPW, DiNisio M, et al. Mechanisms of heparin induced anti-cancer activity in experimental cancer models. Crit Rev Oncol Hematol. 2007;61(3):195-207.
27. Castelli R, Porro F, Tarsia P. The heparins and cancer: review of clinical trials and biological properties. Vasc Med. 2004;9(3):205-213.

28. Marchetti M, Vignoli A, Russo L, et al. Endothelial capillary tube formation and cell proliferation induced by tumor cells are affected by low molecular weight heparins and unfractionated heparin. Thromb Res. 2008;121(5):637-645.

29. Bae KH, Mok H, Park TG. Synthesis, characterization, and intracellular delivery of reducible heparin nanogels for apoptotic cell death. Biomaterials. 2008;29(23):3376-3383.

30. Casu B, Guerrini M, Guglieri S, et al. Undersulfated and glycol-split heparins endowed with antiangiogenic activity. J Med Chem. 2004; 47(4):838-848.

31. Smorenburg SM, Van Noorden CJ. The complex effects of heparins on cancer progression and metastasis in experimental studies. Pharmacol Rev. 2001;53(1):93-106.

32. Farge D, Debourdeau P, Beckers M, et al. International clinical practice guidelines for the treatment and prophylaxis of venous thromboembolism in patients with cancer. $J$ Thromb Haemost. 2013;11(1):56-70.

33. Min Y, Akbulut M, Kristiansen K, et al. The role of interparticle and external forces in nanoparticle assembly. Nat Mater. 2008;7(7): 527-538.

34. Cho H-J, Yoon HY, Koo H, et al. Self-assembled nanoparticles based on hyaluronic acid-ceramide (HA-CE) and Pluronic ${ }^{\circledR}$ for tumor-targeted delivery of docetaxel. Biomaterials. 2011;32(29):7181-7190.

35. Park K, Lee GY, Park R-W, et al. Combination therapy of heparindeoxycholic acid conjugate and doxorubicin against squamous cell carcinoma and B16F10 melanoma. Pharm Res. 2008;25(2): 268-276.

36. Park K, Lee GY, Kim Y-S, et al. Heparin-deoxycholic acid chemical conjugate as an anticancer drug carrier and its antitumor activity. J Control Release. 2006;114(3):300-306.

37. Lee JS, Go DH, Bae JW, et al. Synthesis and characterization of heparin conjugated Tetronic ${ }^{\mathbb{R}}$-PCL copolymer for protein drug delivery. Curr Appl Phys. 2007;7:e49-e52.

38. Li S, Byrne B, Welsh J, et al. Self-assembled poly(butadiene)-b-poly (ethylene oxide)polymersomes as paclitaxel carriers. Biotechnol Prog. 2007;23(1):278-285.

39. Lim Soo P, Eisenberg A. Preparation of block copolymer vesicles in solution. J Polym Sci B Polym Phys. 2004;42(6):923-938.

40. Clarke SJ, Rivory LP. Clinical pharmacokinetics of docetaxel. Clin Pharmacokinet. 1999;36(2):99-114.

41. Mu CF, Balakrishnan P, Cui FD, et al. The effects of mixed MPEGPLA/Pluronic copolymer micelles on the bioavailability and multidrug resistance of docetaxel. Biomaterials. 2010;31(8):2371-2379.

42. He C, Hu Y, Yin L, et al. Effects of particle size and surface charge on cellular uptake and biodistribution of polymeric nanoparticles. Biomaterials. 2010;31(13):3657-3666.

43. Conner SD, Schmid SL. Regulated portals of entry into the cell. Nature. 2003;422(6927):37-44.

44. You J, Hu F-Q, Du Y-Z, et al. High cytotoxicity and resistant-cell reversal of novel paclitaxel loaded micelles by enhancing the molecular-target delivery of the drug. Nanotechnology. 2007;18(49):495101.

45. Termsarasab U, Cho H-J, Kim DH, et al. Chitosan oligosaccharidearachidic acid-based nanoparticles for anti-cancer drug delivery. Int $J$ Pharm. 2013;441(1-2):373-380.

46. Park K, Kim K, Kwon IC, et al. Preparation and characterization of self-assembled nanoparticles of heparin-deoxycholic acid conjugates. Langmuir. 2004;20(26):11726-11731.

47. Rosenberg RD. Heparin, antithrombin, and abnormal clotting. Annu Rev Med. 1978;29(1):367-378.

48. Gaucher G, Dufresne M-H, Sant VP, et al. Block copolymer micelles: preparation, characterization and application in drug delivery. J Control Release. 2005;109(1):169-188.

49. Lee JS, Go DH, Bae JW, et al. Heparin conjugated polymeric micelle for long-term delivery of basic fibroblast growth factor. J Control Release. 2007;117(2):204-209. 
50. Kratohvil JP, Hsu WP, Kwok DI. How large are the micelles of di- $\alpha$ hydroxy bile salts at the critical micellization concentrations in aqueous electrolyte solutions? Results for sodium taurodeoxycholate and sodium deoxycholate. Langmuir. 1986;2(2):256-258.

51. Rizkalla N, Range C, Lacasse F-X, et al. Effect of various formulation parameters on the properties of polymeric nanoparticles prepared by multiple emulsion method. J Microencapsul. 2006;23(1):39-57.

52. Lee AY, Levine MN, Baker RI, et al. Low-molecular-weight heparin versus a coumarin for the prevention of recurrent venous thromboembolism in patients with cancer. $N$ Engl J Med. 2003;349(2):146-153.

53. Nishioka J, Goodin S. Low-molecular-weight heparin in cancerassociated thrombosis: treatment, secondary prevention, and survival. J Oncol Pharm Pract. 2007;13(2):85-97.
54. Jordan MA, Kamath K. How do microtubule-targeted drugs work? An overview. Curr Cancer Drug Targets. 2007;7(8):730-742.

55. Thorpe PE, Derbyshire EJ, Andrade SP, et al. Heparin-steroid conjugates: new angiogenesis inhibitors with antitumor activity in mice. Cancer Res. 1993;53(13):3000-3007.

56. Lapierre F, Holme K, Lam L, et al. Chemical modifications of heparin that diminish its anticoagulant but preserve its heparanase-inhibitory, angiostatic, anti-tumor and anti-metastatic properties. Glycobiology. 1996;6(3):355-366. 


\section{Supplementary materials}

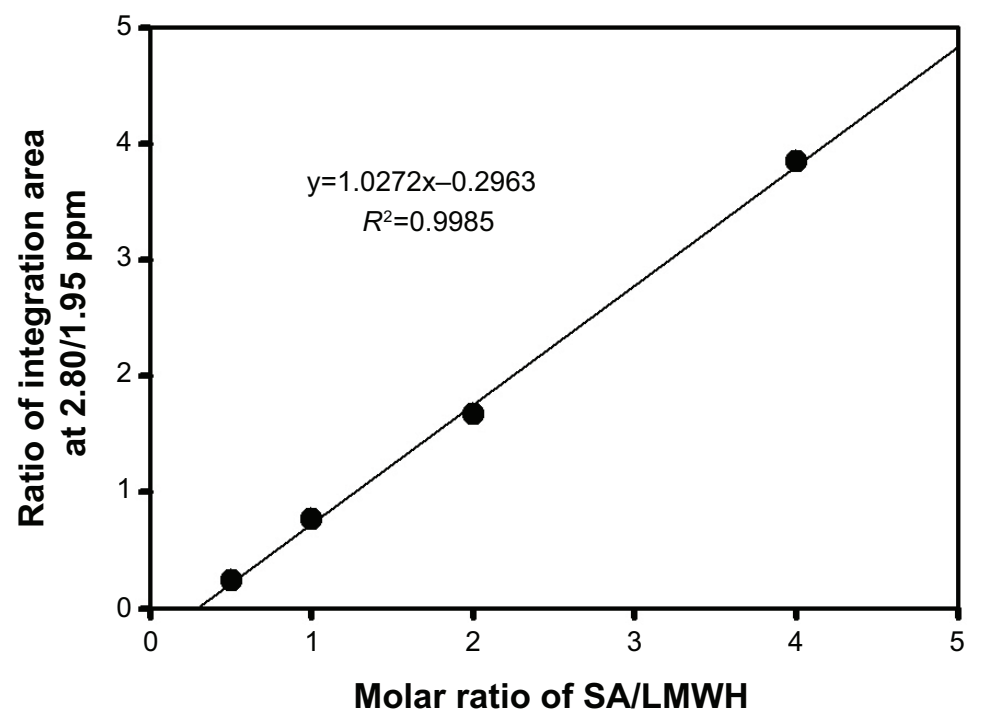

Figure SI Relationship between the ratio of integration area $(2.80 / 1.95 \mathrm{ppm})$ and molar ratio of SA/LMWH based on their physical mixture. Notes: Samples were dissolved in $\mathrm{D}_{2} \mathrm{O} / \mathrm{THF}-\mathrm{d}_{8}$ mixture ( $\left.\mathrm{I}: \mathrm{I}\right)$ for ' $\mathrm{H}$ NMR analysis. Each point represents the mean \pm SD ( $\mathrm{n}=3$ ).

Abbreviations: SA, stearylamine; LMWH, low-molecular-weight heparin.

A

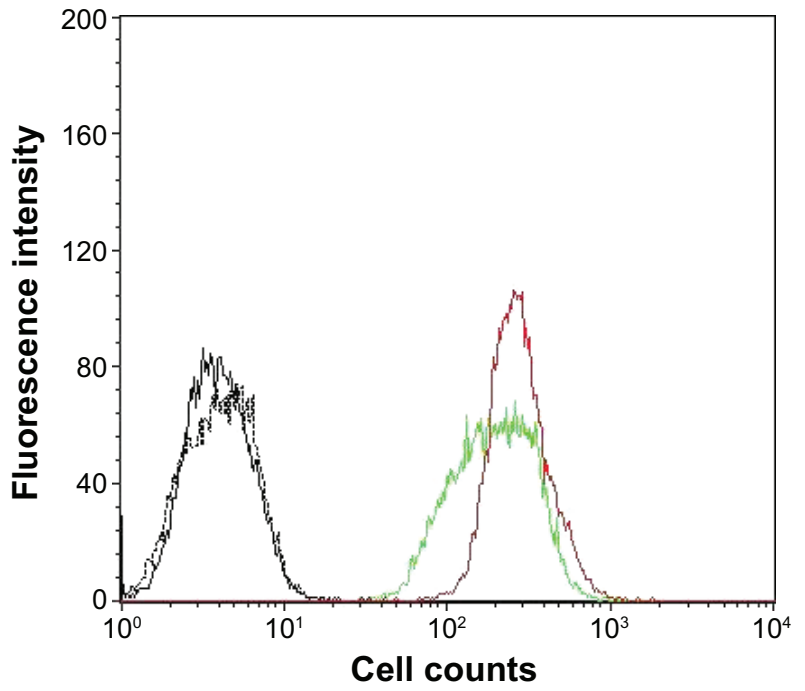

B

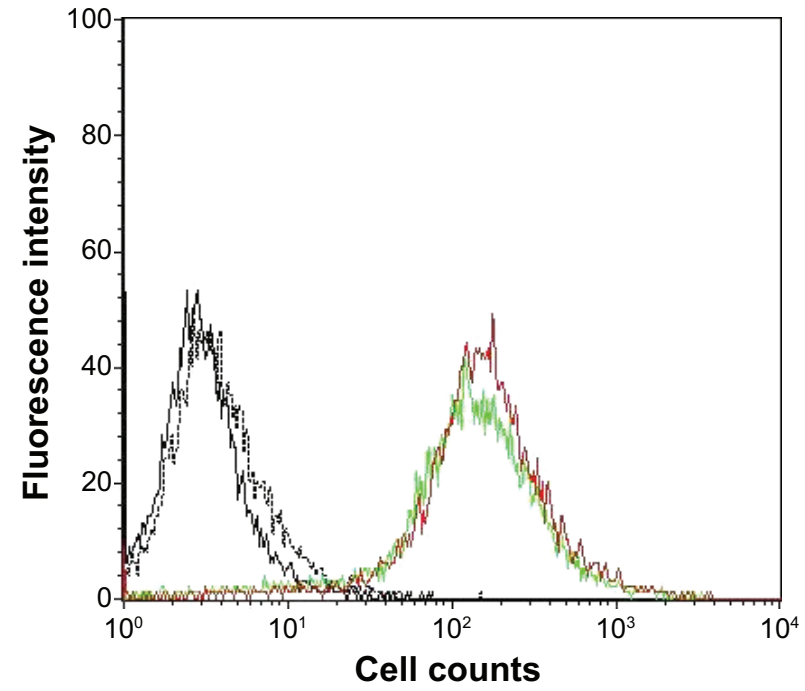

Figure S2 In vitro cellular uptake of coumarin 6 was observed by flow cytometry in (A) MCF-7 and (B) MDAMB 23I cells after incubating for 2 hours.

Note: Groups were as follows: control (black, solid), blank LHSA5 nanoparticles (black, dotted), coumarin 6 solution (green, solid), coumarin 6-loaded LHSA5 nanoparticles (red, solid).

\section{Publish your work in this journal}

The International Journal of Nanomedicine is an international, peerreviewed journal focusing on the application of nanotechnology in diagnostics, therapeutics, and drug delivery systems throughout the biomedical field. This journal is indexed on PubMed Central, MedLine, CAS, SciSearch ${ }^{\circledR}$, Current Contents ${ }^{\circledR} /$ Clinical Medicine,
Journal Citation Reports/Science Edition, EMBase, Scopus and the Elsevier Bibliographic databases. The manuscript management system is completely online and includes a very quick and fair peer-review system, which is all easy to use. Visit http://www.dovepress.com/ testimonials.php to read real quotes from published authors.

\footnotetext{
Submit your manuscript here: http://www.dovepress.com/international-journal-of-nanomedicine-journal
} 